\title{
Genome-wide association mapping in a diverse spring barley collection reveals the presence of QTL hotspots and candidate genes for root and shoot architecture traits at seedling stage
}

Adel H. Abdel-Ghani ${ }^{1+}$, Rajiv Sharma ${ }^{2,3^{*}+}$, Celestine Wabila ${ }^{2}$, Sidram Dhanagond ${ }^{2}$, Saed J. Owais ${ }^{1}$, Mahmud A. Duwayri ${ }^{4}$, Saddam A. Al-Dalain ${ }^{5}$, Christian Klukas ${ }^{2,6}$, Dijun Chen ${ }^{2,7}$, Thomas Lübberstedt ${ }^{8}$, Nicolaus von Wirén ${ }^{2}$, Andreas Graner ${ }^{2,9}$, Benjamin Kilian ${ }^{2,10}$ and Kerstin Neumann ${ }^{2^{*}}$ (D)

\begin{abstract}
Background: Adaptation to drought-prone environments requires robust root architecture. Genotypes with a more vigorous root system have the potential to better adapt to soils with limited moisture content. However, root architecture is complex at both, phenotypic and genetic level. Customized mapping panels in combination with efficient screenings methods can resolve the underlying genetic factors of root traits.

Results: A mapping panel of 233 spring barley genotypes was evaluated for root and shoot architecture traits under non-stress and osmotic stress. A genome-wide association study elucidated 65 involved genomic regions. Among them were 34 root-specific loci, eleven hotspots with associations to up to eight traits and twelve stressspecific loci. A list of candidate genes was established based on educated guess. Selected genes were tested for associated polymorphisms. By this, 14 genes were identified as promising candidates, ten remained suggestive and 15 were rejected. The data support the important role of flowering time genes, including HvPpd-H1, HvCry2, HvCO4 and HVPRR73. Moreover, seven root-related genes, HERK2, HVARF04, HVEXPB1, PIN5, PIN7, PME5 and WOX5 are confirmed as promising candidates. For the QTL with the highest allelic effect for root thickness and plant biomass a homologue of the Arabidopsis Trx-m3 was revealed as the most promising candidate.

Conclusions: This study provides a catalogue of hotspots for seedling growth, root and stress-specific genomic regions along with candidate genes for future potential incorporation in breeding attempts for enhanced yield potential, particularly in drought-prone environments. Root architecture is under polygenic control. The co-localization of well-known major genes for barley development and flowering time with QTL hotspots highlights their importance for seedling growth. Association analysis revealed the involvement of HvPpd-H1 in the development of the root system. The co-localization of root QTL with HERK2, HVARF04, HVEXPB1, PIN5, PINT, PME5 and WOX5 represents a starting point to explore the roles of these genes in barley. Accordingly, the genes HvHOX2, HsfA2b, HvHAK2, and Dhn9, known to be involved in abiotic stress response, were located within stress-specific QTL regions and await future validation.
\end{abstract}

Keywords: Barley, Candidate genes, Genome-wide association study, Osmotic stress, Root architecture

\footnotetext{
* Correspondence: Rajiv.Sharma@hutton.ac.uk; neumannk@ipk-gatersleben.de

${ }^{\dagger}$ Adel H. Abdel-Ghani and Rajiv Sharma should be considered as joint first

authors.

${ }^{2}$ Leibniz Institute of Plant Genetics and Crop Plant Research (IPK),

Corrensstrasse 3, 06466 Seeland, Germany

Full list of author information is available at the end of the article
}

(c) The Author(s). 2019 Open Access This article is distributed under the terms of the Creative Commons Attribution 4.0 International License (http://creativecommons.org/licenses/by/4.0/), which permits unrestricted use, distribution, and reproduction in any medium, provided you give appropriate credit to the original author(s) and the source, provide a link to the Creative Commons license, and indicate if changes were made. The Creative Commons Public Domain Dedication waiver (http://creativecommons.org/publicdomain/zero/1.0/) applies to the data made available in this article, unless otherwise stated. 


\section{Background}

Drought stress is the principal constraint of barley production in West Asia and North Africa (WANA) $[1,2]$ with only one third of the yield compared with Europe [3], mainly because of low $(<300 \mathrm{~mm})$ and unpredictable season-to-season inter-variability in rainfall. Improving crop performance and grain yield and stability under drought is a major goal of plant breeding programs targeting these regions. Crops can be exposed to drought during their entire life cycle from vegetative to reproductive stages [4-6]. Water shortage can cause severe problems to seedlings, restricting the emergence of seedlings, seedling growth and development and thus affecting grain yield [7, 8]. Vigorous root systems are often considered as a primary target to breed for drought tolerance [9-13]. The importance of root traits as indirect selection criteria to increase yield was revealed by recent studies showing a significant positive relationship between root traits at seedling stage and grain yield under drought conditions in barley [14-17], wheat $[18,19]$ and in maize [5].

To assess root architecture traits in the field, vertical root pulling force (RPF) has been used, which is laborious, technically demanding and of insufficient precision [20-22]. As alternatives, high-throughput laboratory screens for root architecture evaluation, such as hydroponic or gel chamber-based systems [23-26] have become available in conjunction with imaging-based methods allowing for simultaneous analysis of multiple traits [27-30]. Robust high-throughput laboratory screens can be used to screen large numbers of genotypes within a short period and limited space [31-34].

In addition, root traits are easier to be assessed under control versus stressful growth conditions [2, 11, 35]. To date, most genetic studies on drought stress were based on visual phenotyping of above-ground plant parts in field studies [36-40]. Assessing root traits in hydroponically-grown seedlings is a valid approach for genetic studies, especially when large numbers of individuals are required for reliable trait quantification [41, 42]. Genome-wide association studies (GWAS) represent a powerful method for studying complex traits in cereals [4346]. A meta-QTL analysis in rice identified 119 QTL for 29 root architecture traits from 24 studies distributed over the whole rice genome, indicating a complex inheritance of root traits [47]. In line with [47], QTL studies indicate a complex nature of root architecture being under polygenic control in barley [e.g. [21, 33, 48-51] ], wheat $[19,52-54]$ and maize [55-57]. Root architecture can also be influenced by abiotic stress but only few studies addressed this topic [21, 49, 58, 59]. Further, we found no report about any root QTL in barley specific for drought conditions.
There is only limited knowledge in barley of candidate genes known to influence root growth. Auxin as a plant hormone plays a role in growth throughout various developmental stages and is involved in root initiation as well as cell division and extension, and regulates gene expression for instance, via auxin response factors (ARFs) [60]. Posttranslational modification of ARF7 was shown to regulate root branching in Arabidopsis [61]. Recently, twenty ARFs were identified in the barley genome [62]. A well-known example for a root architecture gene in monocots is DRO1 in rice that regulates root angle and was discovered by positional cloning of a QTL for deep rooting [63]. In barley, the gene HVEXPB1 has been recently described to cause root hair initiation encoding the cell wall-loosening protein EXPANSIN [64]. The barley gene HvWAK1 is encoding a cell wall-associated receptor-like kinase, which are essential for growth and development. It was shown that its expression is root-specific and that $H v W A K 1$ mutants differed in root growth under non-stress and salt stress conditions compared to the wildtype [65].

Further genes with an influence on both root and shoot growth are the Rht dwarfing genes in wheat [66], the semi-dwarfing genes $s d w 1$ and ari-e.GP in barley [67] and also VRN1 in both crops [68].

The high heritabilities of seedling root and shoot characteristics obtained in hydroponic experiments [69] in a diverse spring barley panel paved the way to employ GWAS to study their genetic architecture. Benefitting from recent achievements in barley genomics [70] GWAS can be efficiently combined with genomic information to discover candidate genes associated with root developmental traits.

The objectives of this study were (i) to investigate the phenotypic variation of selected root and seedling traits in a diverse panel of spring barley genotypes, (ii) to unravel their genetic architecture by performing GWAS based on a large array of SNP markers and (iii) to identify candidate genes underlying hotspots of Quantitative Trait Loci (QTL) under two contrasting water availability treatments.

\section{Methods \\ Mapping panel}

A total of 233 spring barley genotypes was used for phenotypic analysis (Additional file 1: Table S1). Most barley lines (223) originate from a panel harboring broad genetic and phenotypic diversity that was successfully employed in genome-wide association scans for a variety of traits, for instance [46, 59, 71-73]. This panel was selected from IPK's Genebank and was single seed descended twice. Additionally, eight modern two-rowed cultivars and two parents of a double-haploid $(\mathrm{DH})$ population were included in this study. The total collection of 233 lines consists of 135 
(58\%) two-rowed and 98 (42\%) six-rowed genotypes of world-wide origin [69].

\section{Experimental set-up with and without application of osmotic stress}

Root architecture traits were measured in two independent experiments under variable water availability. The experimental procedure was described previously [69]. In short, four 3-day old seedlings for each genotype were placed on filter paper (size $30 \times 20 \mathrm{~cm}$ ) and wrapped into rolls. Rolls were maintained in Hoagland nutrient solution in the absence or presence of $15 \% \mathrm{w} / \mathrm{v}$ polyethylene glycol (PEG) 6000 in a growth chamber with $16 / 8 \mathrm{~h}$ of light at $20 / 18^{\circ} \mathrm{C}$ at a light intensity of $200 \mu \mathrm{mol}$ photons $\mathrm{m}-2 \mathrm{~s}-1$ and $70 \%$ relative humidity. Within each treatment, two paper rolls per genotype were evaluated. Root and seedling traits were recorded 17 days after germination individually for three seedlings of each roll except for root dry weight that was measured based on all roots from all three seedlings per roll due to their very low weights (Table 1). Two consecutive experiments were carried out. Each separate experiment was laid out in a randomized complete block design (RCBD) with split-plot arrangement of the two replications per treatment as main plot and genotype as sub-plot factor. Barley genotypes were randomized within the main plots.

\section{Phenotyping of seedling trait architecture}

Previously, we investigated seven traits from this seedling assay (maximum root length, root dry weight, shoot dry weight, total seedling biomass, root to shoot ratio, shoot length, and drought susceptibly index based on seedling biomass) [69].

For this study, four additional image-based traits derived from scanned seminal roots (Additional file 2: Figure S1) were analyzed: total root length, number of the main roots addressing seminal root number, total root volume and average root thickness (Table 1). All seminal roots of each seedling plant per filter paper roll (three per roll) were separated and placed into a flat bowl filled with water and scanned (Epson Expression 10,000 XL). The images had a resolution of $2044 \times 2219$ pixels. For image analysis, we used the automated root analysis pipeline implemented in the IAP software [74]. The analysis of the images followed four main steps: (i) pre-processing -images were prepared for segmentation, (2) segmentation - images were divided into different parts which have different meanings (for example, foreground - the root part; background - imaging chamber) with K-means based auto-tuning, (3) removal of small noise objects and root skeletonization, and (4) post-processing - to summarize calculated results for each root. More details are provided in [74].

\section{Statistical analysis of phenotypic traits}

Analyses of variance (ANOVA) were calculated using the following model: $y_{j k i}=\mu+G_{j}+E_{i}+B_{k(i)}+G E_{j i}+\varepsilon_{j k i}$, where $y_{j k i}$ represents the individual observation of the $j k i^{t h}$ experimental unit, $\mu$ is the grand mean, $E_{i}$ is the effect of $i^{t h}$ independent experiment, $B_{k(l)}$ is the effect of $k^{\text {th }}$ block nested in $i^{\text {th }}$ experiment, $G_{k}$ is the effect of $k^{\text {th }}$

Table 1 Trait list, abbreviations and description

\begin{tabular}{|c|c|c|c|c|}
\hline \multirow[t]{2}{*}{ Trait } & \multicolumn{2}{|c|}{ Abbreviation $^{++}$} & \multicolumn{2}{|c|}{ Description } \\
\hline & Non-Stress & Stress & Unit & \\
\hline Root dry weight $^{+}$ & Rdwc & Rdws & $\mathrm{mg}$ & $\begin{array}{l}\text { Roots were dried at } 70^{\circ} \mathrm{C} \text { for } 48 \mathrm{~h} \text { and their weights were recorded using a weighing } \\
\text { balance (Sartorius } \mathrm{AC} 1215 \text {, Germany). }\end{array}$ \\
\hline Shoot dry weight ${ }^{+}$ & Sdwc & Sdws & $\mathrm{mg}$ & $\begin{array}{l}\text { Shoots were dried at } 70^{\circ} \mathrm{C} \text { for } 48 \mathrm{~h} \text { and their weights were recorded using a weighing } \\
\text { balance (Sartorius } \mathrm{AC} 1215 \text {, Germany). }\end{array}$ \\
\hline Total plant biomass ${ }^{+}$ & Byc & Bys & $\mathrm{mg}$ & $\begin{array}{l}\text { Dry weights of shoots and roots were summed to get biomass/ biological yield of } \\
\text { the seedlings. }\end{array}$ \\
\hline Root to shoot ratio ${ }^{+}$ & Rsc & Rss & ratio & It is measured as ratio of Root to Shoot dry weights. \\
\hline Maximum root length ${ }^{+}$ & $\mathrm{Rlc}$ & Rls & $\mathrm{cm}$ & Using scaled ruler maximum root lengths/ root length was measured. \\
\hline Shoot length ${ }^{+}$ & Slc & Sls & $\mathrm{cm}$ & Scaled ruler was used to record the shoot length of the seedlings. \\
\hline Number of main roots & Nmrc & Nmrs & No. & Based on images of the scanned roots number of roots were recorded. \\
\hline Average root thickness & Rthc & Rths & $\mathrm{mm}$ & Based on images of the scanned roots average root thickness were recorded. \\
\hline Total root length & Trle & Trls & $\mathrm{mm}$ & $\begin{array}{l}\text { All roots were considered in recording the total root length based on images of } \\
\text { the scanned roots. }\end{array}$ \\
\hline Total root volume & Trve & Trvs & $\mathrm{mm}^{3}$ & $\begin{array}{l}\text { All roots were considered in recording the total root volume based on images of } \\
\text { the scanned roots. }\end{array}$ \\
\hline Drought susceptibility index & DSI & & & $\begin{array}{l}\text { It is calculated using the formula of Fisher and Maurer (1978) using Biological yield } \\
\text { of control and stress see more details in Adel-Ghani et al. (2015). }\end{array}$ \\
\hline
\end{tabular}


genotype, $G E_{j i}$ is the interaction effect of the $i^{\text {th }}$ experiment with $k^{t h}$ genotype, and $\varepsilon_{\mathrm{jki}}$ is the residual. The experiment was fitted as a fixed effect, whereas blocks and genotypes were fitted as random effects.

The phenotypic variance $\left(\sigma_{p}^{2}\right)$ was estimated according to the following formula: $\sigma_{p}^{2}=\sigma_{g}^{2}+\frac{\sigma_{g \times e x}^{2}}{n}+\frac{\sigma_{e}^{2}}{n \times r}$, where, $\sigma_{g}^{2}$ is the genotypic variance component, $\sigma_{g \times e x}^{2}$ is the genotype $\times$ experiment variance, $\sigma_{e}^{2}$ is the residual variance component, $\mathrm{r}$ is the number of replicates and $\mathrm{n}$ is the number of experiments. An estimate of the broad-sense heritability $\left(h^{2}\right)$ on plot basis was calculated as the ratio between the genetic $\left(\sigma_{g}^{2}\right)$ and the phenotypic $\left(\sigma_{p}^{2}\right)$ variance [75]. Pearson correlations between traits were calculated in R 3.5 [76].

\section{Genotypic data and genome-wide association scans}

The whole barley panel in this study was genotyped using the $9 \mathrm{~K}$ iSelect array (Illumina, CA, United States) for barley containing 7864 SNPs [77]. After genotype calling, quality control filtering was applied, and markers with poor quality ( $>10 \%$ of missing data) and minor allele frequency (MAF) less than 5\% were excluded from further analysis, leaving 6019 high-quality SNPs. Among them, all mapped SNPs (4966; 82.5\%) were considered for GWAS using the genetic map provided by [77]. Positions of mapped SNPs were further updated according to the Popseq map [78] if information was available.

The GWAS analysis was performed in the R package Genome Association and Prediction Integrated Tools (GAPIT version 2) [79]. Population structure using PCA and kinship was calculated in GAPIT and included in the GWAS model to control false positives. In total, three PCs were incorporated, explaining combined $26 \%$ of the total variation (individually: 16, 6 and 4\%). The SUPER (settlement of MLM under progressively exclusive relationship) method [80] known to increase the statistical power was used to calculate genome-wide associations. To account for false positives due to multiple testing, the false discovery rate (FDR) method (FDR-adjusted, $P<0.05$ ) [81] implemented in GAPIT was applied to the GWAS results. A schematic map indicating QTL positions was drawn using MapChart 2.2 Windows [82].

\section{Candidate gene evaluation}

Candidate genes (CGs) were retrieved from the literature and by screening important QTL regions for annotated high confidence genes employing [83]. Further, the GBS data set of [84], which included the accessions employed in the present study, was screened for SNPs within these CGs and used for CG-association approach after filtering for MAF (> $0.05)$ and missing data $(<10 \%)$. Moreover, genomic fragments of twelve CGs were re-sequenced in the association panel. Genomic DNA was isolated from single leaves of each genotype with the Qiagen DNeasy Plant Mini Kit (Qiagen, Hilden, Germany), according to the manufacturer's instructions. The Primer3 online software [85] was used to design PCR primers. Primers amplified one to two fragments for each CG (Additional file 1: Table S2). PCR products were purified by NucleoFast 96 PCR plates (Macherey-Nagel, Germany) and were sequenced directly on both strands on Applied Biosystems (Weiterstadt, Germany) ABI Prism 3730xL sequencer using BigDye terminators. DNA sequences were processed with $\mathrm{AB}$ DNA Sequencing Analysis Software 5.2 and later manually edited by Bio-Edit version 7.0.9.0 [86].

Sequence alignments were generated with ClustalW, and the allelic haplotypes were defined by DNASP 6.12 [87]. All singletons have been confirmed afterwards by additional three independent amplifications and sequencing.

\section{Results \\ Phenotypic evaluation of seedling trait architecture under contrasting growth conditions}

In total, ten traits were recorded under two different moisture treatments. Additionally, DSI was calculated and used as a derived trait for GWAS. A wide range of phenotypic variation was detected for all traits (Table 1 , Additional file 1: Table S3). The phenotypic BLUEs of all traits along with their variance decreased drastically under stress treatment (Fig. 1). The lowest reductions were observed for $\mathrm{Sl}$ and $\mathrm{Sdw}$ (7 and 9\%, respectively), while the strongest reductions were obtained for Trv and $\mathrm{Rdw}$ (50 and 36\%, respectively). Considerable reductions in the coefficient of variation $(\mathrm{CV})$ in the osmotic stress treatment were observed for the four image-based root traits, ranging from $4 \%$ (Rth) to $51 \%$ (Trv) (Additional file 1: Table S3). Furthermore, heritability values were lower under stress (range 0.20-0.68) compared to non-stress conditions (range 0.37-0.78; Additional file 1: Table S4), which is comparable to the manually recorded traits [69]. In both treatments, $\mathrm{Trl}$ and Nmr had the lowest heritability. In non-stress conditions, all further traits exhibited heritabilities $>0.5$, the highest displayed by Rsr (0.78) and Rth (0.75), while in stress conditions, seven traits showed heritabilities $<0.5$. The three traits with higher heritability in stress were $\mathrm{Rl}$, Sdw and Sl (0.68, 0.54 and 0.53, respectively). The lower heritability values and coefficients of variation under imposed stress conditions indicate the complexity of the genotypic response to stress and environmental variation. Further, the reduction response was most pronounced for $\operatorname{Trv}(50.5 \%)$, followed by Rdw and Rl (35.9 and $28.6 \%$, respectively), which suggests that root 


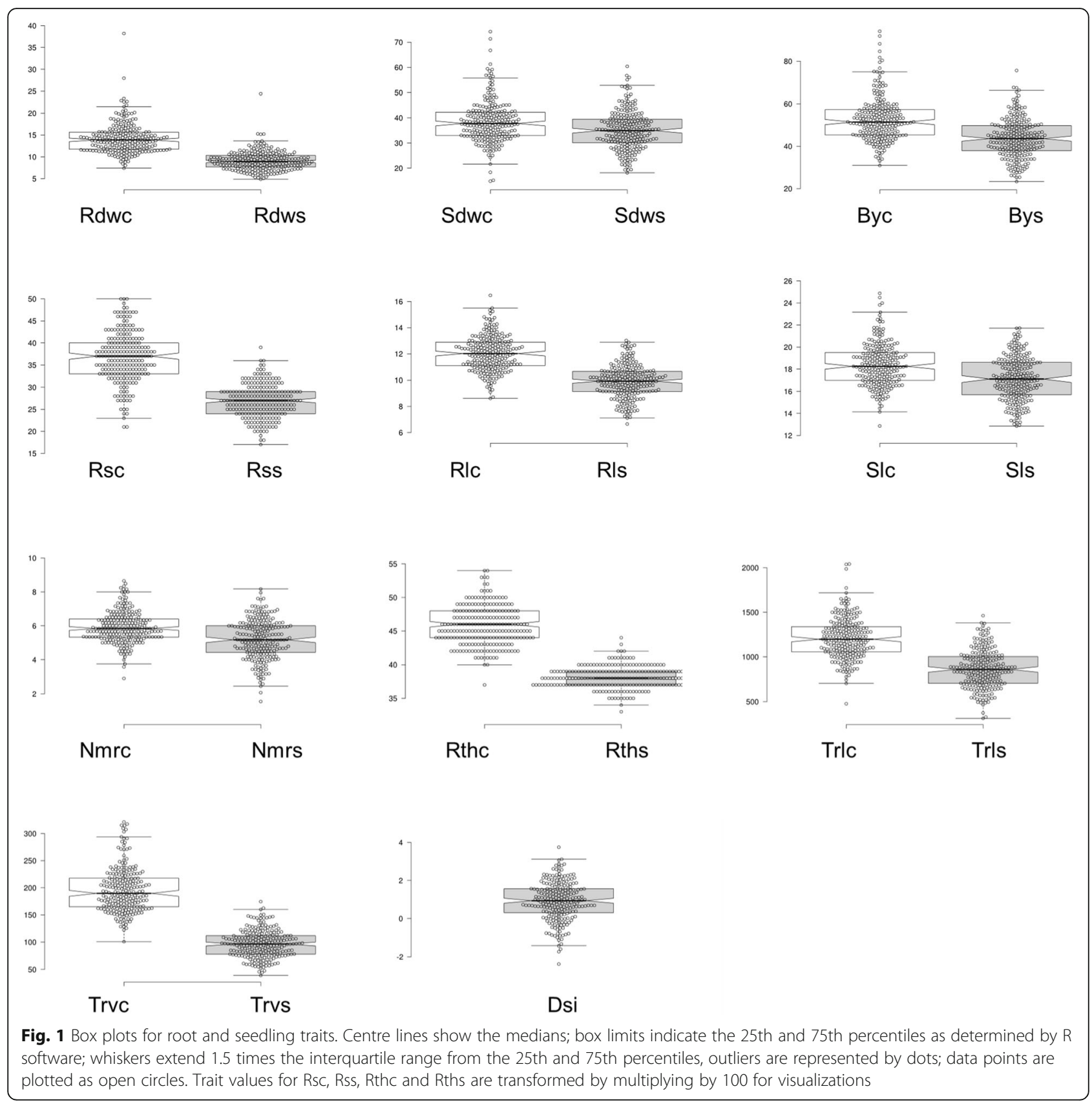

biomass components were affected most when stress was imposed, while Rth and $\mathrm{Nmr}$ were less strong reduced (17.4 and $11.9 \%$, respectively). Least affected were $\mathrm{Sl}$ and Sdw (7.1 and 9.1\%, respectively), demonstrating most accessions were investing more into shoot biomass under osmotic stress.

Significant positive correlations were observed among seedling traits within both treatments, except for Rs (Fig. 2). Among the image-based traits, Trv showed the strongest positive correlation with $\mathrm{Rdw}$ across treatments, whereas $\mathrm{Nmr}$ and Rth displayed moderate to low-correlation values. In general, stress reduced most of the correlations among various traits but they showed similar relationships under both treatments in line with [21].

\section{Influence of population structure}

The present panel comprised 223 genotypes from a well-studied population and ten additional genotypes. Population structure in this population was extensively investigated by [46] and revealed six subgroups based on row type and geographic origin. In GWAS, the kinship was fully sufficient to control for the confounding effects of population structure. Nevertheless, we have investigated population structure in the 


\section{Non-Stress}

\begin{tabular}{|c|c|c|c|c|c|c|c|c|c|c|c|c|c|}
\hline & & Rdwc & Sdwc & Byc & Rsc & RIC & Slc & Nmrc & Rthic & Trlc & Trve & \multirow{2}{*}{ Rdwc } & \multirow{11}{*}{ 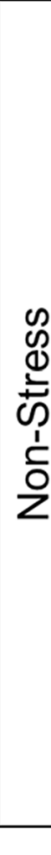 } \\
\hline \multirow{10}{*}{ 吕 } & Rdws & 0.48 & 0.54 & 0.74 & 0.41 & 0.51 & 0.61 & 0.22 & 0.39 & 0.47 & 0.68 & & \\
\hline & Sdws & 0.69 & 0.43 & 0.95 & -0.35 & 0.33 & 0.56 & 0.16 & 0.40 & 0.28 & 0.53 & \multirow{2}{*}{$\begin{array}{c}\text { Sdwc } \\
\text { Byc }\end{array}$} & \\
\hline & Bys & 0.79 & 0.97 & 0.17 & -0.16 & 0.42 & 0.63 & 0.19 & 0.47 & 0.33 & 0.61 & & \\
\hline & Rss & 0.3 & -0.34 & -0.2 & 0.52 & 0.24 & 0.09 & 0.11 & 0.00 & 0.33 & 0.28 & Rsc & \\
\hline & RIs & 0.42 & 0.31 & 0.37 & 0.2 & 0.51 & 0.47 & 0.05 & 0.27 & 0.42 & 0.55 & \multirow{2}{*}{ RIC } & \\
\hline & Sls & 0.54 & 0.67 & 0.67 & -0.16 & 0.33 & 0.60 & 0.19 & 0.29 & 0.42 & 0.59 & & \\
\hline & Nmrs & 0.46 & 0.39 & 0.44 & 0.18 & 0.21 & 0.33 & 0.18 & -0.19 & 0.51 & 0.39 & Nmrc & \\
\hline & Rthis & 0.29 & 0.23 & 0.23 & 0.09 & 0.16 & 0.07 & -0.1 & 0.53 & -0.20 & 0.42 & Rthic & \\
\hline & Trls & 0.59 & 0.55 & 0.61 & 0.15 & 0.51 & 0.52 & 0.72 & -0.06 & 0.31 & 0.77 & Trlc & \\
\hline & Trvs & 0.68 & 0.63 & 0.69 & 0.18 & 0.55 & 0.54 & 0.68 & 0.23 & 0.94 & $0: 45$ & Trve & \\
\hline
\end{tabular}

\section{Stress}

Fig. 2 Correlations between root and seedling traits in non-stress or osmotic stress conditions. Correlations are displayed as heatmap and as numerical value. Red = negative correlation, blue = positive correlation. The part above the diagonal presents correlations of traits only within non-stress treatment and below the diagonal only within stress treatment. Along the diagonal correlations between the same trait in both treatment are displayed. Correlations values above 0.2 and below -0.2 are significant $(P<0.01)$

extended panel using Structure 2.0. In consistence with [46] the collection clustered according to row type and origin (Additional file 1: Table S5, Additional file 2: supplementary note and Figure S2). All nine additional two-rowed genotypes clustered within group 5 (European two-rowed genotypes), while the only additional six-rowed genotype clustered among the six-rowed European group 9. We tested if the main factor of population structure (row type) affected our phenotypic traits. In control, only one trait was significantly different (Trlc), while under stress, six traits showed differences, in all cases two-rowed genotypes were performing better (Additional file 1: Table S6).

\section{Genome-wide association scans for root and shoot traits} A set of 4966 mapped and quality-filtered SNP markers were used for GWAS, which were evenly distributed over all seven chromosomes with an average spacing of $4.97 \mathrm{cM}$. The number of markers varied among chromosomes with a minimum of 483 SNPs on chromosome $1 \mathrm{H}$ and a maximum of 967 SNPs on chromosome 5H (Additional file 1: Table S7).

In total, 519 marker-trait associations were detected (Additional file 1: Table S8), based on 323 SNPs that were associated with one (234 SNPs) and or two and up to five traits (89 SNPs). For all traits analyzed, significant associations were detected for nineteen traits across all seven chromosomes (Figs. 3 and 4), while no significant associations were identified for Nmrs and Dsi.

Associated SNPs in close distance were grouped into QTL regions based on the average LD decay of $\sim 3.5 \mathrm{cM}$ (data not shown) due to differential LD blocks for individual chromosomes and thus a variable decay across the chromosomes (Additional file 2: Figure S3). This enabled us to detect 65 QTL regions (Fig. 5, Additional file 1: Table S8). The highest number of QTL was identified on chromosomes $2 \mathrm{H}$ (13), $5 \mathrm{H}(11), 3 \mathrm{H}(10)$ and $7 \mathrm{H}(10)$, and the lowest found on $6 \mathrm{H}$ (3). In total, 26 out of all 65 QTL regions correspond to traits from both treatments, while 27 and 


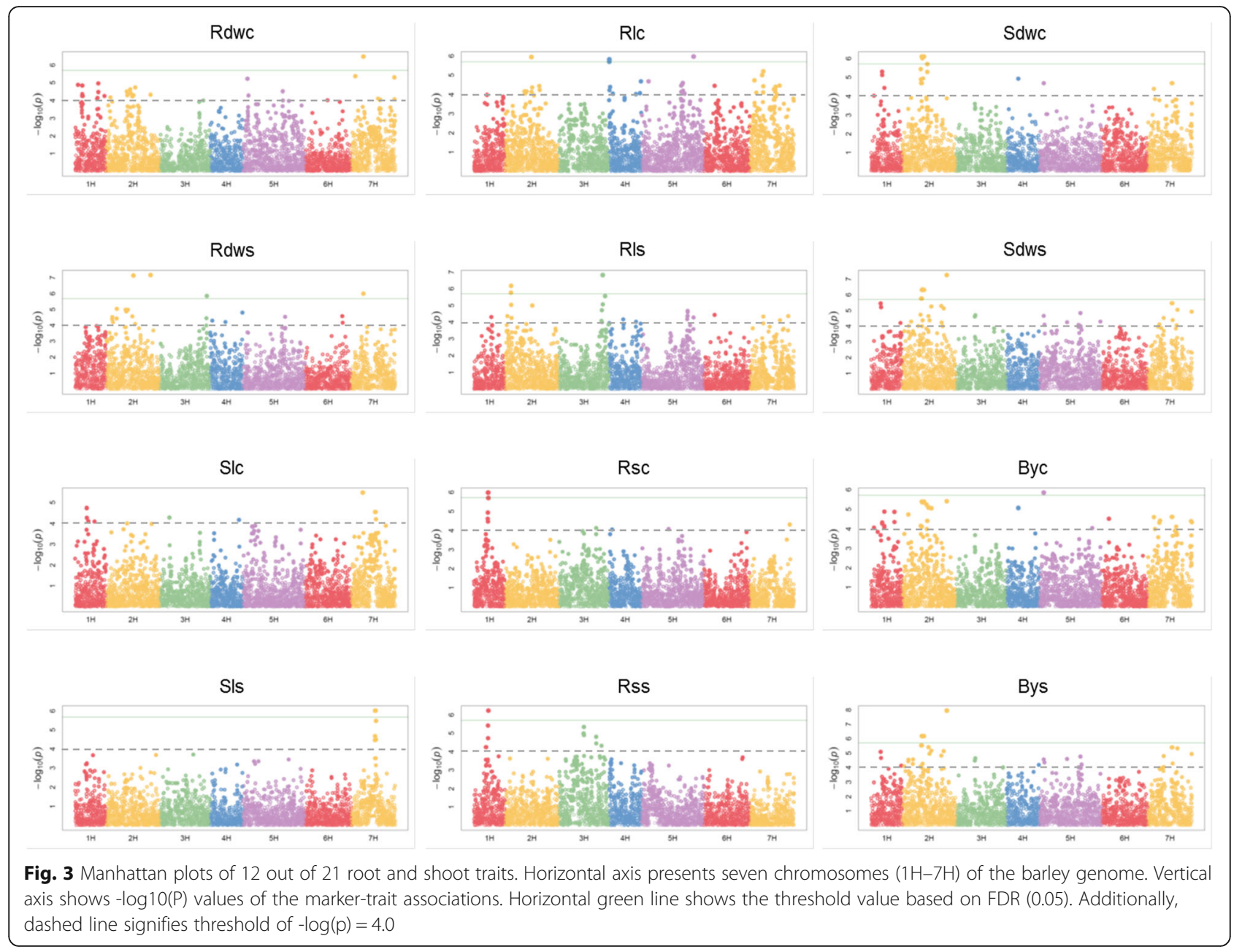

12 correspond to traits from non-stress or stress treatment, respectively. This may reflect the reduced heritabilities obtained under stress conditions.

Further, we defined a QTL as a hotspot QTL if at least five out of all ten traits were associated to this region. In total, we identified eleven hotspot QTL and observed a concentration of five hotspots alone on $2 \mathrm{H}$ (QTL-2H-3, QTL-2H-6, QTL-2H-7, QTL-2H-8, QTL-2H-11), while the remaining were located on $1 \mathrm{H}$ (QTL-1H-3), $4 \mathrm{H}$ (QTL-4H-4), 5H (QTL-5H-1, QTL-5H-6) and 7H (QTL-7H-6, QTL-7H-10). All hotspots were associated with traits from both treatments.

\section{Candidate gene exploration and testing}

By educated guess, a list of candidate genes (CGs) was established (Additional file 1: Table S8). We identified developmental, flowering time, stress-related and root-affecting CGs from the recently annotated barley genome assembly [70]. Additionally, root-morphology related gene homologues from Arabidopsis, rice and maize were identified. Thereby, CGs near to our QTL regions were identified which we think are suitable candidates for the associated traits. However, the approach is not accurate, in particular in the centromeric regions where recombination is low and QTL interval is large. To further test polymorphisms within the potential CGs for associations we assembled the polymorphisms of these CGs by using two approaches i) utilization of GBS data for the IPK barley collection [84] and ii) re-sequencing CG fragments within the association panel.

Out of 113 potential CGs (Additional file 1: Table S8), 128 SNPs from 39 CGs were retrieved by GBS approach. However, after filtering for missing data and MAF, 71 SNPs from 29 CGs were tested for associations to our 21 traits with the same model as in GWAS. Association between traits and CG-SNPs with $-\log (\mathrm{p})$-value $>2$ were obtained for 17 different CGs (Additional file 1: Table S9), revealing a number of 12 CGs that can be excluded as CGs as they had weaker associations. For nine CGs, the $-\log (\mathrm{p})$-value in GWAS was higher in the corresponding QTL region. This suggests that we miss either the causal SNP or we have not hit the right CG and therefore these nine 


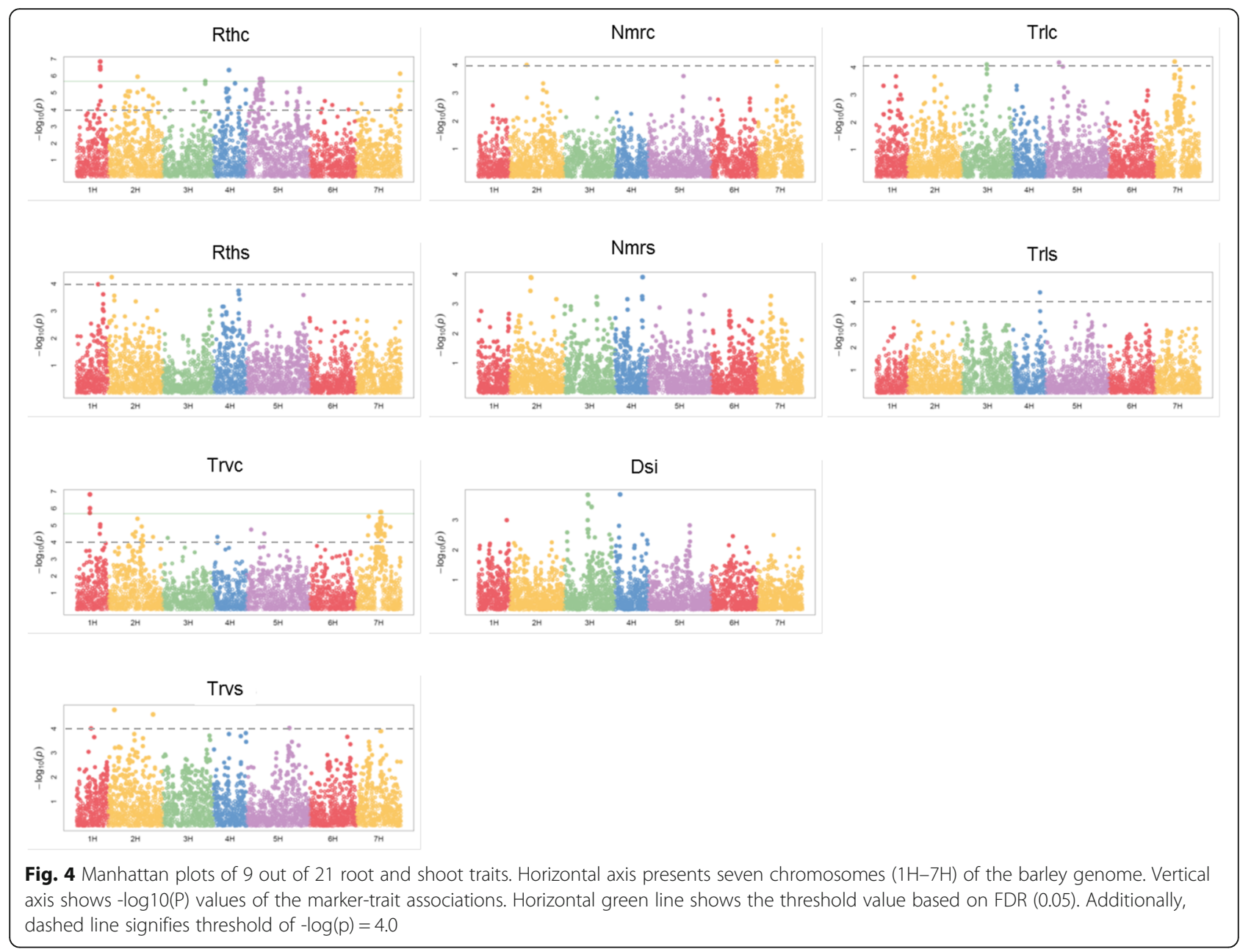

genes remain potential CGs. Nevertheless, 15 associations corresponding to eight CGs were of similar $-\log (\mathrm{p})$-value as in GWAS (difference maximal 0.3 lower) or of even higher $-\log (\mathrm{p})$-value and therefore support the gene as a CG. The most striking result came from a SNP of PIN7 associated with Rthc, where the $-\log (\mathrm{p})$-value was 5.92 while in GWAS the highest was only 4.02 in the corresponding QTL region.

In the second approach, fragments of twelve CGs were re-sequenced for the majority of accessions from the GWAS panel (Additional file 1: Table S2). These genes comprised two flowering time genes ( $H v P p d-H 1$ and $H \nu C E N)$ and ten root growth related candidate genes, two of them chosen outside of QTL regions detected in this study. From the twelve CG fragments, eight showed significant trait associations (Additional file 1: Table S10, Additional file 2: Fig. S4), while four genes were rejected as CGs (HvCEN, ABP1, PRC2, PIN2). Six CGs had associations similar or higher compared to GWAS and are supported as the right CG $(H v P p D-H 1, T R X-m 3$, HvEXPB1, WOX5, PIN5, HvARFO4). The two other genes remain potential CGs ( $H \nu C K X 5$, GNOM).
Two CGs were covered by both approaches, GBS and re-sequencing. Both revealed a rejection of PIN2 as CG behind root-specific QTL-7H-9 and both suggest a role of TRX-m3 as a CG for hotspot QTL-2H-6. Nevertheless, some associations from TRX-m3 based on re-sequencing were similar or higher compared to GWAS and therefore support $T R X-m 3$ as a CG, while by GBS approach the gene remains a potential CG. However, only one SNP form the gene was available in GBS data compared to seven from re-sequencing.

In summary, 39 CGs were tested for associations to phenotypic traits by one or two of the CG-association approaches. In total, fourteen CGs are supported as candidates, while ten remain potential CGs (association not as high as in GWAS) and fifteen can be rejected as a CG (Table 2).

\section{Discussion}

The present study applied GWAS to root and seedling traits in a diverse spring barley panel of world-wide origin. We demonstrate here that in barley traits related to root and shoot architecture are under the regulation of 


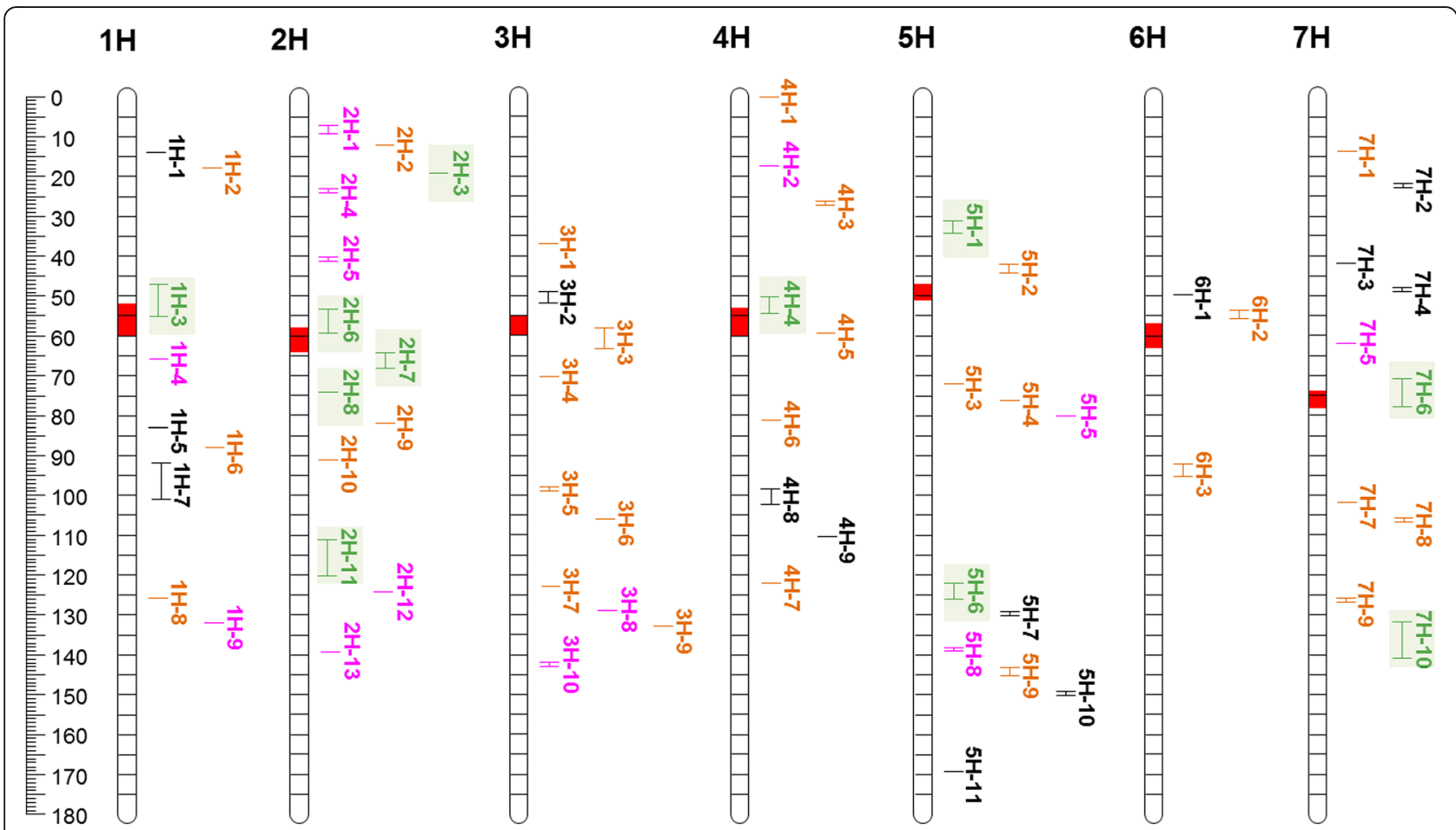

Fig. 5 Genetic positions (CM) of 65 QTL regions for root and shoot seedling architecture placed on a schematic map of the seven barley chromosomes along with the corresponding QTL name (see Additional file 1: Table S5 for all details). QTL-hotspots are highlighted in green, root specific QTL in orange, stress-specific QTL in pink and the remaining non-specific QTL in black. Centromeric regions are indicated by

red segments

at least 65 QTL in line with [47]. Chromosome $2 \mathrm{H}$ harbors the highest number of QTL. Only a single QTL was specific for shoot architecture (QTL-1H-5), while 31 out of all 65 QTL were linked with both root and shoot traits, indicating linkage and/or pleiotropic effects of these QTL. In total, 34 QTL were exclusively associated with root architecture traits; the majority located on $3 \mathrm{H}(8)$, followed by $2 \mathrm{H}, 4 \mathrm{H}$ and 5H (5 QTL each).

By comparing QTL positions found in other studies, we found a number of QTL co-locating with shoot biomass QTL [88] detected in a subset of our collection (QTL-3H-5, QTL-4H-7, QTL-7H-1) and with drought and biomass related QTL in a winter barley collection [89] (Additional file 1: Table S8). Moreover, five root-specific QTL (QTL-2H-4, QTL-2H-10, QTL 3H-4, QTL-5H-6, QTL-5H-9) were co-locating with QTL for agronomic traits in recombinant chromosome substitution lines out of cultivated and wild barley [90], indicating a potential role of these QTL in yield formation.

Further, twelve stress-specific QTL were found on $1 \mathrm{H}$ (2), $2 \mathrm{H}(4), 3 \mathrm{H}(2), 4 \mathrm{H}(1), 5 \mathrm{H}(2)$ and $7 \mathrm{H}(1)$, four of them exclusively found for root traits. To our best knowledge that is the first report on root QTL in barley appearing exclusively under drought stress (QTL-1H-4, QTL-2H-4, QTL-3H-8, QTL-4H-2).
Flowering time-related genes as candidates for root and shoot architecture at seedling stage under non-stress and osmotic stress conditions

For many QTL a co-localization with flowering time-related genes was observed (Additional file 1: Table S8). This may refer to pleiotropic effects of these genes or to genetic linkage of flowering time genes and the causal gene. A QTL study in Brassica revealed a trade of between flowering time and root pulling force (RPF) [91], resulting in co-localization of QTL for flowering time and RPF and also grain yield under both wet and drought conditions in the field. A Wuschel related homeobox (WOX) family protein of the group 13 in Arabidopsis (AtWOX13) affected floral transition and was expressed during primary and lateral root formation [92]. It was shown that $H v P p d-H 1$ directly controls leaf growth in barley [93]. Further, osmotic stress at seedling stage increased the expression of clock-related genes particular for Ppd-H1, HvPRR73 and HvPRR95 in barley [94]. Accordingly, ABA-responsive elements (ABRE) were identified in the promoter sequences of clock genes, leading to the assumption that stress regulates their transcription in barley in line with results from Arabidopsis [95]. It was suggested that circadian clock and light regulators are involved in the transcriptional 
Table 2 Overview of results from candidate gene (CG)-association approach using SNPs from GBS or re-sequencing (RS)

\begin{tabular}{|c|c|c|c|c|c|c|}
\hline GBS CGS & Annotation in BARLEX & $\begin{array}{l}\text { Alternative } \\
\text { names }\end{array}$ & Approach & $\begin{array}{l}\text { CG status } \\
\text { after testing }\end{array}$ & $\begin{array}{l}\text { highest - } \\
\log (p \text { of } C G)\end{array}$ & $\begin{array}{l}\text { Corresponding QTL } \\
\text { region }\end{array}$ \\
\hline HORVU1Hr1G057860 & cytokinin oxidase/dehydrogenase 1 & $\operatorname{AtCKX1}$ & GBS & potential & 2.3 & QTL-1H-3 \\
\hline HORVU1Hr1G080950 & Glycogen synthase & HVSSIV & GBS & potential & 2.05 & QTL-1H-7 \\
\hline HORVU1Hr1G082250 & alcohol dehydrogenase 1 & Adh2 & GBS & supported & 2.21 & QTL-1H-7 \\
\hline HORVU1Hr1G094980 & Early flowering 3 & HVELF3 & GBS & potential & 3.26 & QTL-1H-9 \\
\hline HORVU2Hr1G013400 & pseudo-response regulator 7 & HvPpd-H1 & RS & supported & 5.34 & QTL-2H-3 \\
\hline HORVU2Hr1G036320 & $\begin{array}{l}\text { WRKY family transcription factor family } \\
\text { protein }\end{array}$ & HvSUSIBA2 & GBS & potential & 2.03 & QTL-2H-6 \\
\hline HORVU2Hr1G080630 & 14-3-3-like protein GF14-B & HvGID2 & GBS & potential & 3.55 & QTL-2H-6 \\
\hline HORVU2Hr1G075240 & Thioredoxin superfamily protein & $\operatorname{TRX}-\mathrm{m} 3$ & RS & supported & 5.65 & QTL-2H-6 \\
\hline HORVU2Hr1G075240 & Thioredoxin superfamily protein & $T R X-m 3$ & GBS & potential & 2.73 & QTL-2H-6 \\
\hline HORVU2Hr1G085910 & Zinc finger protein CONSTANS-LIKE 4 & $\mathrm{HvCO} 4$ & GBS & supported & 4.21 & QTL-2H-7 \\
\hline HORVU2Hr1G097490 & expansin B4 & HVEXPB1 & RS & supported & 2.63 & QTL-2H-10 \\
\hline HORVU2Hr1G097380 & pectinesterase 11 & PME5 & GBS & supported & 3.71 & QTL-2H-10 \\
\hline HORVU2Hr1G103780 & protein kinase family protein & HERK2 & GBS & supported & 2.73 & QTL-2H-11 \\
\hline HORVU3Hr1G075920 & Cytokinin dehydrogenase 5 & HvCKX5 & RS & potential & 2.27 & QTL-3H-4 \\
\hline HORVU3Hr1G085050 & WUSCHEL-related homeobox 9 & WOX5 & RS & supported & 3.02 & QTL-3H-5 \\
\hline HORVU3Hr1G089980 & gibberellin 20 oxidase 2 & HVGA200x3 & GBS & potential & 2.51 & QTL-3H-6 \\
\hline HORVU3Hr1G094000 & Auxin efflux carrier family protein & PIN5 & RS & supported & 3.21 & QTL-3H-7 \\
\hline HORVU4Hr1G057550 & pseudo-response regulator 7 & HvPRR73 & GBS & supported & 6.16 & QTL-4H-4 \\
\hline HORVU5Hr1G095530 & phytochrome C & HvPhyC & GBS & potential & 2.15 & QTL-5H-2 \\
\hline HORVU6Hr1G058740 & cryptochrome 2 & HvCry2 & GBS & supported & 2.44 & QTL-6H-2 \\
\hline HORVU6Hr1G076110 & Auxin efflux carrier family protein| & PIN7 & GBS & supported & 5.92 & QTL-6H-3 \\
\hline HORVU7Hr1G074690 & $\begin{array}{l}\text { glyceraldehyde-3-phosphate dehydrogenase } \\
\text { C2 }\end{array}$ & GAPC3 & GBS & potential & 2.16 & QTL-7H-6 \\
\hline HORVU7Hr1G120030 & Delta(24)-sterol reductase & $H v D I M$ & GBS & supported & 2.98 & QTL-7H-10 \\
\hline HORVU7Hr1G033820 & auxin response factor 19 & HVARFO4 & RS & supported & 3.58 & $\begin{array}{l}\text { no QTL between QTL- } \\
7 \mathrm{H}-4 \text { and QTL-7H-5 }\end{array}$ \\
\hline HORVU4Hr1G002880 & $\begin{array}{l}\text { SEC7-like guanine nucleotide exchange } \\
\text { family protein }\end{array}$ & GNOM & RS & potential & 2.02 & $\begin{array}{l}\text { no QTL, between QTL- } \\
4 \mathrm{H}-1 \text { and } \mathrm{QTL}-4 \mathrm{H}-2\end{array}$ \\
\hline HORVU1Hr1G039150 & CCT motif family protein & HVCMF10 & GBS & rejected & $<2$ & QTL-1H-3 \\
\hline HORVU1Hr1G093770 & Lysine-specific demethylase $5 B$ & $\begin{array}{l}\text { HVPKDM7- } \\
1\end{array}$ & GBS & rejected & $<2$ & QTL-1H-9 \\
\hline HORVU2Hr1G072750 & Protein TERMINAL FLOWER 1 & HVCEN & RS & rejected & $<2$ & QTL-2H-6 \\
\hline HORVU2Hr1G113880 & $\begin{array}{l}\text { AP2-like ethylene-responsive transcription } \\
\text { factor }\end{array}$ & Zeo1/AP2 & GBS & rejected & $<2$ & QTL-2H-11 \\
\hline HORVU3Hr1G072810 & gibberellin 2-oxidase & HvGA2OX1 & GBS & rejected & $<2$ & QTL-3H-3 \\
\hline HORVU3Hr1G090980 & gibberellin 20-oxidase 3 & $\begin{array}{l}\text { sdw1 / } \\
\text { denso }\end{array}$ & GBS & rejected & $<2$ & QTL-3H-7 \\
\hline HORVU3Hr1G106880 & $\begin{array}{l}\text { Ankyrin repeat family protein / BTB/POZ } \\
\text { domain-containing protein }\end{array}$ & Uniculme4 & GBS & rejected & $<2$ & QTL-3H-10 \\
\hline HORVU5Hr1G050510 & kinesin 4 & $\begin{array}{l}\text { HvBC12/ } \\
\text { GGD1 }\end{array}$ & GBS & rejected & $<2$ & QTL-5H-2 \\
\hline HORVU5Hr1G026780 & Auxin-binding protein & $A B P 1$ & RS & rejected & $<2$ & QTL-5H-2 \\
\hline HORVU6Hr1G056000 & CONSTANS-like 3 & HvCO5 & GBS & rejected & $<2$ & QTL-6H-2 \\
\hline HORVU6Hr1G057630 & $\begin{array}{l}\text { Two-component response regulator-like } \\
\text { PRR1 }\end{array}$ & HvPRR1 & GBS & rejected & $<2$ & QTL-6H-2 \\
\hline HORVU7Hr1G099250 & Protein VERNALIZATION INSENSITIVE 3 & PRC2 & RS & rejected & $<2$ & QTL-7H-7 \\
\hline
\end{tabular}


Table 2 Overview of results from candidate gene (CG)-association approach using SNPs from GBS or re-sequencing (RS) (Continued)

\begin{tabular}{|c|c|c|c|c|c|c|}
\hline GBS CGS & Annotation in BARLEX & $\begin{array}{l}\text { Alternative } \\
\text { names }\end{array}$ & Approach & $\begin{array}{l}\text { CG status } \\
\text { after testing }\end{array}$ & $\begin{array}{l}\text { highest - } \\
\log (p \text { of } C G)\end{array}$ & $\begin{array}{l}\text { Corresponding QTL } \\
\text { region }\end{array}$ \\
\hline HORVU7Hr1G110470 & Auxin efflux carrier family protein & PIN2 & GBS & rejected & $<2$ & QTL-7H-9 \\
\hline HORVU7Hr1G110470 & Auxin efflux carrier family protein & PIN2 & RS & rejected & $<2$ & QTL-7H-9 \\
\hline HORVU7Hr1G120520 & sucrose synthase 6 & HvSuSyll & GBS & rejected & $<2$ & QTL-7H-10 \\
\hline HORVU7Hr1G120960 & callose synthase 1 & HVGSL5 & GBS & rejected & $<2$ & QTL-7H-10 \\
\hline
\end{tabular}

If a SNP showed associations with - $\log (\mathrm{p})$-value $>2$, the highest association is presented. The column CG status summarizes the result of testing for associations in comparison to GWAS

control of stress-response genes. Moreover, Bowman and Scarlett introgression lines varying at $H v E L F 3$ and $H v P p d-H 1$ possessed a lower biomass under osmotic stress compared with their recurrent parents [94]. These studies demonstrate the role of flowering time genes on seedling growth and stress tolerance. Therefore, flowering time-related genes can be causal genes behind several of our QTL. In total, eleven of them were covered by the one of the two CG-association approaches. Supported as CGs for

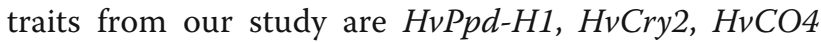
and $H v P R R 73$, while $H v G I D 2, H v E L F 3$, and $H v P h y C$ remain potential CGs. A role of $H \nu C E N$, $H \nu C M F 10$, HvCO5 and HvPRR1, as CGs behind QTL from our study was rejected by the CG-association approaches.

\section{Genes known to be involved in root growth are located} in the vicinity of detected root-specific QTL

Half of all QTL were specific for root architecture and represent the most interesting regions to screen for genes involved in root growth. There is a very limited number of candidate genes presently known to influence root growth in barley.

Half of the twenty identified ARFs in barley [62] are located in the vicinity of QTL identified in our study (Additional file 1:Table S8): hotspots QTL-2H-6 (HvARF12), QTL-2H-8 (HvARF15), QTL-2H-11 (HvARF09) and QTL-5H-1 (HvARF07) and root-specific QTL-3H-3 (HvARF18), QTL-3H-7 (HvARF10, HvARF11), QTL-7H-7 (HvARF16) and QTL-7H-8 (HvARF06) and the non-specific QTL-1H-7 (HvARF19). Unfortunately, none of these ten ARFs was covered by the GBS CG-association approach. However, we re-sequenced HvARF04 (located outside of detected QTL regions) and detected strong associations to Rthc and Rsc $(-\log (\mathrm{p})>3)$. This undermines the role of ARFs in root architecture and encourages re-sequencing of these genes in our collection.

We further mapped barley homologues to Arabidopsis PIN-FORMED (PIN) genes (PIN2, PIN5, PIN7 and PIN8) [96-100], which encode auxin transporters that control radial root growth [101]. They were mapped in the genomic regions of QTL-7H-9 (Rls and Rsc, third highest allelic effect for Rsc), QTL-3H-7 at $122.6 \mathrm{cM}$ (Rthc), QTL-6H-3 (Rdws and Rthc) and QTL-3H-3 (Rthc, Trlc and Rss, third highest allelic effect for Rss and Trlc), respectively. Mutations in these genes have been reported to cause severe root phenotypes due to de-regulated auxin transport [102]. The QTL-7H-9 region was further reported to be associated with rhizosheath weight in barley [50]. Two of these genes are strongly supported as candidates behind detected QTL in our study by CG-association approaches, namely PIN5 and PIN7, while PIN2 was rejected as a CG. GNOM, a gene involved in the endosomal recycling of the auxin-efflux carrier PIN1 in Arabidopsis [103] evolved as a potential $\mathrm{CG}$ by re-sequencing efforts. Interestingly, for $\mathrm{Nmr}$ we detected only two QTL by GWAS. With the GBS CG-association approach, three further QTL for Nmr were detected and the highest association came from PIN7.

We found three associations to root traits (Rlc, Trvc, Rthc) for the root-specific QTL-2H-10 containing the CG HvEXPB1. This QTL had the highest allelic effect on Trvc and the third highest effect for Rlc. Close by, [50] mapped a QTL for rhizosheath weight in barley at 94.2 $\mathrm{cM}$, highlighting the role of this QTL in different genetic background. However, one SNP of QTL-2H-10 (SCRI_RS_195164) was also associated with biomass under drought stress in winter barley [89]. Accordingly, $H v E X P B 1$ was associated with Bys and Sdws in the GBS CG-association approach. This indicates an effect of $H v E X P B 1$ in drought adaptation. Further supported by GBS CG-association approach is PME5 that was associated exclusively with traits form control conditions (Rls, Slc, Trlc). The gene is encoding for a Pectin Methylesterase that contribute to control of cell wall growth and development [104] and also play a role in the process of root inhibition by aluminum [105]. Recently, [106] showed that PME5 expression leads to stronger cell walls. Depending on the trait, different genes in the QTL region might be the causal gene. Interestingly, also a QTL for hectoliter weight [90] was mapped to the QTL-2H-10 region and therefore indicates a link of seedling traits to yield formation.

The QTL-3H-5 region was associated with Rsc and Rss (second highest allelic effect). A QTL for Rdw (96.7 cM) in close vicinity was identified earlier by [59] using 223 genotypes that are part of our GWAS panel. A 
homologue to the Arabidopsis auxin transporter gene $A U X 1$, which is involved in lateral root development [107] and a homologue to WUSCHEL-RELATED HOMEOBOX5 (WOX5) - a gene related to root organogenesis - are located in very close proximity to QTL-3H-5. Also, the flowering time gene $H v C M F 1$ is located within the QTL region and may cause pleiotropic effects on root growth. Only WOX5 could be tested in the CG-association approach and is supported as CG by re-sequencing.

In the recent past, several candidate genes affecting root development were isolated from cereals. The predicted position of root hairless 3 (RTH3) [108] is in the region of hotspot QTL-4H-4, where five root and shoot traits showed significant associations. Within the vicinity of root specific QTL-4H-7, a CG is located with high sequence similarity to adventitious rootless1 (ARL1) and seminal roots, crown rootless 1 (CRL1) in rice $[109,110]$ and rootless concerning crown (RTCS) in maize [111]. These genes affect the initiation of adventitious and crown root formation, respectively, by regulating polar auxin transport. The region of QTL-4H-7 might also affect above ground trait architecture indicated by the co-localisation with a shoot biomass QTL [89].

The QTL-5H-2 was detected for Rthc, Rlc, Trlc and Trvc and showed the highest allelic effect for Trvc. Interestingly, in this QTL region [51] located QTL for RDW, Rl and Rs. Further, seven of all 44 SNPs from that QTLregion were also associated with biomass in control or in drought conditions in winter barley [89]. QTL-5H-2 coincides with a QTL for tiller number found in the smaller subset of the collection [71] but none of the SNPs from QTL-5H-2 is identical to the 26 significant SNPs from [88]. Therefore, different CGs might be causal for these traits but in the centromeric region resolution is low and the right candidate hard to identify. The region contains many genes including flowering time genes such as HvCMF13, HvCO3, HvPRR95 and $H v P h y C$. Using the GBS CG-association approach, $H v P h y C$ evolved as a potential CG, while the other three CGs were not tested for associations.

Another root-specific QTL-6H-2 harbors three flowering time genes. From $\mathrm{H} v \mathrm{Cry} 2, \mathrm{H \nu CO}$, and HvPRR1, $\mathrm{H \nu Cry} 2$ is supported by GBS CG-association approach as a candidate, while $\mathrm{H \nu CO5}$ and $H \nu P R R 1$ were rejected.

The root specific QTL-7H-1 associated with Rlc, RDWc and Rthc harbors the waxy locus encoding for a granule-bound starch synthase I (GBSS I), which catalyzes the synthesis of amylose synthesis in developing grains [112]. As a secondary effect, developing seedlings might have better conditions for early growth as they feed from the starch stored in the grain. Accordingly, a QTL for early shoot biomass was detected in the smaller two-rowed subset of the present collection [88].
However, HvWAXY could not be tested for associations and should be re-sequenced to unravel its role as a CG.

Hotspot QTL for root and shoot seedling architecture under contrasting growth conditions

The present study showed the occurrence of eleven QTL hotspots for root and shoot traits from both treatments on five chromosomes. QTL hotspots for yield-related traits were reported in barley [e.g. [113116] ], while for root and shoot traits at seedling stage, information is limited. In chickpea, [117] reported one QTL hotspot for root traits including root length density, suggesting that pleiotropic effects for root architecture traits may exist as a common feature in crop plants.

In our study, hotspot QTL-1H-3 was associated with six traits. For Rsc, Rss and Trvc, this QTL had the highest allelic effects for Rsc and Rss. Seven SNPs of QTL-1H-3 were associated with seedling biomass in control conditions or with DSI in winter barley [89], indicating this genomic region has an impact on plant growth in broader genetic background, at different growth stages and under contrasting growth conditions. Located within QTL-1H-3 region resides GA INSENSITIVE DWARF 1 (HvGID1) affecting plant height and growth, and therefore representing a strong candidate for this hotspot. Also, the flowering time gene $H \nu C M F 10$ is located in the region and may have pleiotropic effects. Further, the SIX-ROWED SPIKE3 (Vrs3) is located in this region. This gene has been reported to cause effects on lateral grain size and grain uniformity $[118,119]$ and acts as a transcriptional activator of row-type genes like Vrs1 and int-C which affects tillering and shoot branching [120]. However, a role of Vrs3 in modifying root traits is unknown. A root-related CG represents AtCKX1, a cytokinin oxidase/dehydrogenase. Cytokinins have an important but opposite role in growth of roots and shoots [121]. They modulate root elongation and the number of lateral roots [122]. By the GBS CG-association approach, AtCKX1 remains a potential CG, while $H \nu C M F 10$ was rejected. HvGID1 and Vrs3 were not tested.

Hotspot QTL-2H-3 harbors the major locus of flowering time in spring barley $H \nu P p d-H 1$, a PSEUDO-RESPONSE REGULATOR [62]. In previous studies, the association of $H v P p d-H 1$ with many agronomic traits has been well elaborated [72, 123-127]. Recently, $H v P p d-H 1$ was shown to directly influence leaf growth by it's involvement in leaf meristem activity under long-day conditions [93, 128]. Our GWAS panel differs for photoperiod sensitivity [72] and our experiments were performed under long day conditions [69]. The re-sequencing CG-association approach of a 1367 bp gene fragment supported $H v P p d-H 1$ as the causal gene behind QTL-2H-3. High associations, including the functional SNP [129], were found for root and shoot biomass under osmotic stress and non-stress conditions, 
demonstrating the effect of $H v P p d-H 1$ also on root growth which was unknown so far. Nevertheless, not all traits from this hotspot, namely Rthc, Trls and Trvs, were associated with SNPs within $H v P p d-H 1$, indicating that additional unknown genes in this region might cause the effects for these three traits.

Among the five QTL hotspots on 2H, QTL-2H-6 and QTL-2H-7 are located in the peri-centromeric region which has reduced recombination [130] and harbors several CGs known to affect root morphology. QTL-2H-6 was the QTL with the highest allelic effects for Byc, Bys, Nmrc, Rthc, Sdwc and Sdws and the second highest effects for Rdws and Rlc. In accordance, [51] reported a major QTL for shoot dry weight "QSdw.2H.a" and QTL for RDW and RS in this region. Additionally, a QTL for osmotic adjustment was mapped by [89] in winter barley to the same region. In the region of QTL-2H-6, resides a barley homologue to the Arabidopsis thaliana transcription factor SHORT ROOT (SHR) [131], which regulates radial patterning of the ground tissue in roots and modifies root morphology. Two further genes are located in this region, which are homologous to Prolyl-4-hydroxylase (AtP4H) and Thioredoxin-m3 $(\operatorname{Tr} x-m 3)$ in Arabidopsis $[132,133]$ linked in root meristem and root hairs development.. Furthermore, the gene HvHOX2 is located in this region, encoding for homeodomain-leucine zipper (HD-Zip) I transcription factor regulating in cereals the plant's response to abiotic stresses, including osmotic stress [134]. In addition, auxin transcription factor HvARF12 is located within QTL-2H-6 region and the major flowering time gene $H \nu C E N$. The presence of many plausible CGs in the centromeric region harboring QTL-2H-6 indicates different genes might be causal for the different traits in that hotspot. By the re-sequencing CG-association approach, we rejected $H \nu C E N$. An unexpected, striking result came from $T r x-m 3$ that is supported by the re-sequencing CG-association approach as potential causative gene for Rthc and Byc (the QTL had the highest allelic effects for these traits) and for Trvc. None of the other CGs was tested for associations.

The hotspot QTL-2H-7 is associated with six root and shoot traits. Very close to this region, a QTL for vegetative biomass at $68.6 \mathrm{cM}$ was identified by [89]. The region harbors $\mathrm{H \nu CO} 4$, a flowering time gene. Another interesting CG represents MutS HOMOLOG1 (MSH1). The MSH1 protein targets plastids and mitochondria and is involved in genome stability. However, surpression or loss of the gene has huge impact on altered development and enhanced growth vigour by epigentic changes $[135,136]$. There is implication that MSH1 acts as environmental sensor and stress signal transmission [137]. Nothing is known yet about phenotypic effects of natural variation of MSH1. A QTL hotpsot for early seedling growth under control and osmotic stress conditions in its vicinity encourages future research in this direction. MSH1 was not tested in our CG-association approaches. However, $\mathrm{HvCO} 4$ evolved as a strong candidate for Rthc by GBS CG-association approach.

Another hotspot QTL associated with six root and shoot traits is QTL-2H-8. In close proximity a biomass QTL was found in the study of [89]. A candidate might be $H v A R F 15$, an auxin transcription factor that could not be tested as a CG.

Five traits associated to the hotspot QTL-2H-11 with highest significance for Sdwc and the second highest allelic effects for Sdws and Trvs. Accordingly, QTL for biomass and DSI were mapped to this region by [89]. Furthermore, a SNP of QTL-2H-11 associated with Rthc (SCRI_RS_200949), was detected as a QTL for rhizosheath weight [50], indicating a high relevance of this hotspot for root traits. One CG for this locus represents HvAPETELA2 (HvAP2/EREBP) that affects pollination by expanding the lodicule size in the floret; in mutants the density of the grains in the spike increased along with a decrease of the internode length of the stem and spike $[138,139]$. It is possible that the same gene also affects below-ground root traits by modifying traits like root weight or thickness. AP2/ERF transcription factors are further known to be induced by osmotic stress [140]. Another CG for this locus represents HvARFO9, an auxin transcription factor. Moreover, a gene with role in cell elongation HERK2 is located in this region, having an antagonistic role in root and hypocotyl elongation [141]. This gene was supported by the GBS CG-association approach.

The only hotspot QTL of $4 \mathrm{H}(\mathrm{QTL}-4 \mathrm{H}-4)$ ), is among the most three important QTL for Byc and Sdwc in terms of allelic effects and is harboring the flowering time genes $H v P h y B$ and $H v P R R 73$. Further, the region contains the root gene RTH3. QTL for root shoot ratio [51] and for for osmotic adjustment [89] were reported for this region. Therefore, the region may harbor also stress tolerance related genes. However, the centromeric region contains many genes hampering the identification of the underlying gene(s) of this locus. By the GBS CG-association approach $H v P R R 73$ is supported as a CG for Rth.

Hotspot QTL-5H-1 is among the three most important QTL for Byc, Rdwc and Sdwc in size of allelic effects and further coincides with a tiller number QTL in the vegetative stage in a subset of our collection [88] and with a QTL for biomass and DSI in winter barley [89]. One CG represents $H v N C E D 1$ that is located in very close proximity to QTL-5H-1. The nine-cis-epoxycarotenoid dioxygenase $(N C E D)$ catalizes the rate-limiting step in ABA biosynthesis [142]. Aside from auxin, ABA influences root growth by cell 
divison and elongation [143]. Further, ABA is involved in controlling root and shoot growth under drought conditions [144]. Another CG for this hotspot is HvARFO7, an auxin transcription factor. None of the two CGs were tested.

In our study hotspot QTL-5H-6 had the the third highest allelic effect on Sdws. VRN-H1, a major gene determining the requirement of vernalization, is located within the region. Further, VRN-H1 coincided with the chromosomal location of a yield and biomass QTL in barley under drought conditions in Syria [145], while [68] reported that $V R N-H 1$ exhibits pleiotropic effects on root and plant morphology in wheat and barley. However, also the root-specific $H \nu W A K 1$ is located in this region. This gene represents a further interesting candidate for re-sequencing.

Hotspot QTL-7H-6 was associated with eight traits from both treatments. This region contains $\mathrm{HvCO}$, the barley homologue to CONSTANS in Arabidopsis [146, 147]. Expression of $\mathrm{H \nu CO1}$ accelerates inflorescence development and stem elongation [148]. It is tempting to speculate that this gene might also affect root architecture. The barley clock homologue $H \nu C C A 1 / H \nu L H Y$ [149] is also located within the QTL-7H-6 interval. This genomic region was further associated with multiple traits identified in previous studies in barley, like tiller number, phase duration, rhizosheath weight and biomass $[50,72,89,123]$. Tillering and plant height is affected by MONOCULM 1 (MOC1) which is located within this region [150]. Another CG could be an orthologue of OsGAPC3, encoding for glyceraldehyde-3-phosphate dehydrogenase shown to enhance salt tolerance in rice seedlings [151]. Therefore, co-localization of many agronomic QTL in that hotspot region might very well arise from different CGs depending on the phenotypic trait. By GBS CG-association approach the supposed barley orthologue of OsGAPC3 remains a potential CG.

Hotspot QTL-7H-10 showed the third highest allelic effect for Rthc. Two SNPs of the region at 140.8$140.9 \mathrm{cM}$ were associated with Byc, Bys, Rthc and Sdws, and at the same position (but a different SNP) a strong QTL for vegetative biomass was identified in a subset of the collection [88] and in other collections $[50,89]$. QTL for tiller number [123] in the same region indicate the importance of the region for biomass related traits across different germplasm pools and growth stages. The region harbors several growth-related CGs such as HvDIM, HvGsl5, HvSuSyII and an ent-copalyl diphosphate synthase. Interestingly, $H v D I M$ is supported as a CG by the GBS CG-association approach, while HvGsl5 and HvSuSyII were rejected. However, SNPs from HvDIM detected in the GBS CG association approach were associated with Sls, SLs and Trlc, although no significant QTL was detected by GWAS for these traits in the region of QTL-7H-10.

Stress-specific QTL regions at seedling stage

In total, twelve QTL were classified as stress-specific in our study. Six coincided with QTL found by [89] using a vegetative drought at the tillering stage (Additional file 1: Table S8).

The first was QTL-2H-1, significant for Bys, Rls and Rths and possessing the highest allelic effect for Rths. QTL for biomass in drought and well-watered conditions were found in close proximity [89]. A potential CG represents the pglcat6 gene, encoding for a beta-3-glucuronyltransferase. In Arabidopsis, a beta-3-glucuronyltransferase was shown to be involved in cell elongation at the seedling stage [152].

QTL-2H-4 was significant for Rdws and Rls and co-locates with a QTL for the DSI [89]. QTL for harvest index and TKW under rain-fed conditions were mapped to the same position [90], revealing a suggestive role of this QTL under natural dry conditions. A heat stress transcription factor (HSF) $H s f A 2 b$ is located in very close proximity to this stress-specific QTL. HSFs have a regulating role for stress-responsive genes under various types of abiotic stresses such as heat, drought or salinity [153].

QTL-2H-5 was associated with Sdws, Rdws, Bys and co-locates with a QTL for DSI in winter barley [89]. It coincides with a QTL for biomass under drought in a subset of our mapping panel (Dhanagond et al.; in preparation). The region is promising to harbor CGs for drought tolerance. Among the annotated genes in this QTL region, we identified $H v H A K 2$ as a CG, a potassium transporter of the KUP6 family, which are key factors in osmotic adjustment [154].

QTL-2H-12 was exclusively linked with Sdws in our study but co-locates with a QTL for vegetative tiller number in well-watered conditions in a smaller subset of the present collection [88] and with a QTL for biomass in well-watered conditions in winter barley [89] and therefore might not be truly stress-specific.

QTL-5H-5 was associated with Bys and Sdws and was for both traits among the most three important QTL in terms of allelic effects. Moreover, QTL for biomass under drought stress and for osmotic adjustment were identified in this region [89], thereby raising interest in the underlying genes. However, the corresponding SNP is not validated in the physical map of barley and therefore identification of CGs is hampered.

QTL-5H-8, trait specific for Rls, co-locates with a biomass QTL during drought stress in a subset of the collection (Dhanagond et al.; in preparation). In winter barley, QTL for DSI and biomass and for osmotic adjustment were mapped to the same region [89], undermining the importance of this genomic region for stress 
tolerance. In the vicinity of this QTL is located $\operatorname{Dhn} 9$, a gene known to be involved in drought tolerance. Dehydrins are a group of late embryogenesis abundant proteins forming in response to drought [155].

A QTL for Rs was identified by [51] within the vicinity of QTL-7H-5. Very close to the QTL maps the Vegetative to Reproductive Transition gene 2 (HvVRT-2), a SVP-like gene delaying floral transition and induced by cold [156]. However, a role in drought response is unknown. In proximal position to QTL-7H-5 resides $H v A B F 2$ belonging to a subclass of bzip- transcription factors that regulate ABA stress response [157]. Expression of ABFs is induced by abiotic stress [158] and it was shown that overexpression of ABF2 leads to slower germination and growth of young seedlings and further to increased drought, heat and salt tolerance in Arabidopsis [159]. This gene is therefore a strong CG for this locus but was not tested in the CG-association approaches.

The remaining five stress-specific QTL did not co-locate with QTL from other studies and might be specific for seedling stage stress tolerance or specific for our spring barley panel.

\section{Conclusions}

This study demonstrates that in barley a wide range of natural genetic variation exists for root and seedling traits that can be exploited for crop improvement. In total, 65 genomic regions underlying root and shoot architecture and osmotic stress tolerance at seedling stage were identified by GWAS. This demonstrates the rich genetic diversity of the well-characterized spring barley mapping panel. However, future studies should address winter barley to compare the genetic architecture across both germplasm pools. In total, 14 CG were supported by CG-association approaches. Findings suggest that the flowering time genes $\mathrm{HvPpd}-\mathrm{H} 1, \mathrm{HvCry2}, \mathrm{HvCO} 4$ and $H v P R R 73$ are potentially involved in root and shoot formation and osmotic stress tolerance. A direct role of $H v P p d-H 1$ on root growth should be investigated. The co-localization of detected root QTL to auxin response factors and PIN-FORMED genes and the support for three of these genes (HvARF04, PIN5, PIN7) from CG-association approaches encourages further research on their role in barley. Moreover, further root-related genes were supported: HERK2, HVEXPB1, PME5, and WOX5. Trx-m3 was supported as CG for Rthc and Byc within the most important QTL region for these two traits. Our results highlight these candidates as genes with future potential in breeding for enhanced early vigor and a better root system. QTL regions were identified for osmotic stress tolerance and potential candidates comprise $H s f A 2 b, H v A B F 2, H v H A K 2$ and Dhn9.

\section{Additional files}

Additional file 1: Table S1.Overview of 233 genotypes used in this study, their accession numbers, collection name, origin, row type and biological status. Table S2.Candidate genes re-sequenced in the association panel with primer combinations used. Details are provided for amplified fragment sizes, primer combinations and annealing temperature Table S3.Summary statistics of ten root and shoot seedling traits and for DSI. Table S4.Estimates of variance components and broad sense heritabilities under non- stress and 15\% PEG drought stress conditions. Table S5.Analysis of Molecular Variance (AMOVA) for the 233 diverse barley genotypes based on $K=9$, employing 6019 SNP markers. Table S6.Influence of row-type on the phenotypic traits: t-test results and phenotypic mean values for both row-types. Table S7.Distribution of mapped SNPs across seven barley chromosomes, coverage and polymorphism information content (PIC). Table S8. Summary of the significant QTL. Trait names, SNP marker names, chromosome, genetic positions, $p$-value of the associated SNP, minor allele frequency (MAF), $R^{2}$ value of the SNP model with and without model, allelic effects, - log(p)value, QTL-names, and candidate genes along with the marker physical map positions are provided. Table S9. Summary of significant SNPs from candidate genes covered by GBS. Table S10.Summary of significant SNPS from candidate genes covered by re-sequencing. (XLSX $181 \mathrm{~kb}$ )

Additional file 2: Figure S1. Examples of scanned root images from individual plants. Figure S2. Concatenated split network tree for the collection of 233 accessions based on 6019 SNP markers. Figure S3. LD pattern along the individual chromosomes of barley. Figure S4.

Schematic representation of the eight re-sequenced candidate genes models. (DOCX 3427 kb)

\section{Abbreviations}

BLUEs: best linear unbiased estimates; CG: candidate gene; FDR: false discovery rate; GWAS: genome-wide association study; LD: linkage disequilibrium; QTL: quantitative trait locus; SNP: single-nucleotide polymorphism

\section{Acknowledgments}

We thank Nils Stein for discussions and the GABI-GENOBAR and the CROP. SENSe.net consortia for collaboration. We thank the Deanship of Academic Research at Mutah University for releasing Dr. Abdel-Ghani from his work duties at the university during his scientific visits at IPK. We are thankful to Katrin Trnka to assist with the lab work regarding the re-sequencing approach

\section{Funding}

The authors are indebted to the Deutsche Forschungsgemeinschaft (DFG, projects KI 1465/8-1 and KI 1465/9-1) and Deutscher Akademischer Austauschdienst (DAAD, project ID A/14/05106) for supporting Dr. AbdelGhani's scientific visits to the Leibniz Institute of Plant Genetics and Crop Plant Research (IPK). Further, we are thankful for funding of Sidram

Dhanagond by the Federal Ministry of Education and Research of Germany in the frame of the BARSELECT project (0315969D). The funding bodies had no role in the design of the study or collection, analysis, and interpretation of data and neither in writing the manuscript. Publication costs are defrayed by IPK.

\section{Availability of data and materials}

The data sets supporting the conclusions of this article are available in the additional files and from the corresponding authors (Rajiv.Sharma@hutton.ac. uk; neumannk@ipk-gatersleben.de).The acquisition of plant material used in this study complies with institutional, national, and international guidelines. Seeds of the barley collection can be provided on request under the conditions outlined in the Standard Material Transfer Agreement (SMTA).

\section{Authors' contributions}

AHA-G conceived, designed and conducted the experiments and analyzed the phenotypic data. DC and CK developed the root image analysis pipeline and analysed the scanned root images. AHA-G, RS and CW performed GWAS for all traits. SD, RS and BK re-sequenced candidate genes and RS performed candidate gene association analysis. AHA-G, RS and KN were the major 
contributors in writing the manuscript. SAAD, SJO, MAD, TL, NvW, AG, BK were involved designing the study, data interpretation and writing of the manuscript. All authors read and approved the final manuscript.

\section{Ethics approval and consent to participate}

Not applicable.

\section{Consent for publication}

Not applicable.

\section{Competing interests}

All the authors declare that they have no conflict of interest.

\section{Publisher's Note}

Springer Nature remains neutral with regard to jurisdictional claims in published maps and institutional affiliations.

\section{Author details}

'Department of Plant Production, Faculty of Agriculture, Mutah University, Mutah, Karak 61710, Jordan. 'Leibniz Institute of Plant Genetics and Crop Plant Research (IPK), Corrensstrasse 3, 06466 Seeland, Germany. ${ }^{3}$ Division of Plant Science, University of Dundee at JHI, Invergowrie, Dundee DD2 5DA, UK. ${ }^{4}$ Department of Horticulture and Agronomy, Faculty of Agriculture, University of Jordan, Amman, Jordan. ${ }^{5}$ Al-Shoubak University College, Al-Balqa' Applied University, Al-, Salt 19117, Jordan. ${ }^{6}$ Digitalization in Research \& Development (ROM), BASF SE, 67056 Ludwigshafen, Germany. ${ }^{7}$ Department for Plant Cell and Molecular Biology, Institute for Biology, Humboldt University Berlin, 10115 Berlin, Germany. ${ }^{8}$ Department of Agronomy, Agronomy Hall, lowa State University, Ames, IA 50011, USA. ${ }^{9}$ Martin-Luther-University Halle-Wittenberg, Betty-Heimann-Str. 3, 06120 Halle/Saale, Germany. ${ }^{10} \mathrm{Global}$ Crop Diversity Trust, Platz der Vereinten Nationen 7, 53113 Bonn, Germany.

\section{Received: 6 December 2018 Accepted: 13 May 2019}

\section{Published online: 23 May 2019}

\section{References}

1. Abdel-Ghani AH. Selection of high yielding lines from heterogeneous Jordanian barley landraces under well watered and drought stress conditions. Bulletin of Faculty of Agriculture. Cairo University Bull Fac Agric. 2013;(64):13-29

2. Solh $M$, van Ginkel $M$. Drought preparedness and drought mitigation in the developing World's drylands. Weather Clim Extrem. 2014;3:62-6.

3. Food and agriculture Organization of the United Nations. FAO statistical yearbook 2013.

4. Ceccarelli S. Specific adaptation and breeding for marginal conditions. Euphytica. 1994;77:205-19.

5. Abdel-Ghani AH, Kumar B, Reyes-Matamoros J, Gonzalez-Portilla PJ, Jansen C, Martin JPS, et al. Genotypic variation and relationships between seedling and adult plant traits in maize (Zea mays L.) inbred lines grown under contrasting nitrogen levels. Euphytica. 2012;189(1):123-33.

6. Shavrukov Y, Kurishbayev A, Jatayev S, Shvidchenko V, Zotova L, Koekemoer $F$, et al. Early flowering as a drought escape mechanism in plants: how can it aid wheat production? Front Plant Sci. 2017:8:1950

7. Al-Karaki GN. Response of wheat and barley during germination to seed osmopriming at different water potential. J Agron Crop Sci. 1998;181:229-35.

8. Haddadin MF, Abdel-Ghani AH, Al-Majali NF. Response of barely varieties to drought stress imposed at different developmental stages. Jordan J Agric Sci. 2013;9:507-24

9. Richards RA, Passioura JB. Seminal root morphology and water use of wheat I. environmental Effects1. Crop Sci. 1981;21:249.

10. Grando S, Ceccarelli S. Seminal root morphology and coleoptile length in wild (Hordeum vulgare ssp. spontaneum) and cultivated (Hordeum vulgate ssp. vulgare) barley. Euphytica. 1995;86:73-80.

11. Kashiwagi J, Krishnamurthy L, Upadhyaya HD, Krishna H, Chandra S, Vadez V, et al. Genetic variability of drought-avoidance root traits in the mini-core germplasm collection of chickpea (Cicer arietinum L.). Euphytica. 2005;146: 213-22.

12. Comas LH, Becker SR, Cruz VMV, Byrne PF, Dierig DA. Root traits contributing to plant productivity under drought. Front Plant Sci. 2013;4:442.
13. Hellal FA, El-Shabrawi HM, Abd El-Hady M, Khatab IA, El-Sayed SAA, Abdelly C. Influence of PEG induced drought stress on molecular and biochemical constituents and seedling growth of Egyptian barley cultivars. Journal of Genetic Engineering and Biotechnology. 2018;16(1):203-12.

14. Chloupek O, Dostál V, Středa T, Psota V, Dvořáčková O. Drought tolerance of barley varieties in relation to their root system size. Plant Breed. 2010;129: 630-6.

15. Sayed M. QTL analysis for drought tolerance related to root and shoot traits in barley (Hordeum vulgare L.). PhD thesis University of Bonn. http://hss.ulb. uni-bonn.de/2011/2521/2521.pdf. 2011

16. Chen G, Krugman T, Fahima T, Chen K, Röder M, Nevo E, Korol A. Chromosomal regions controlling seedling drought resistance in Israeli wild barley, Hordeum spontaneum C. Koch. Genet Resour Crop Evol. 2010;57:85.

17. Svačina P, Středa T, Chloupek O. Uncommon selection by root system size increases barley yield. Agron Sustain Dev. 2013;34:545-51.

18. Atkinson JA, Wingen LU, Griffiths M, Pound MP, Gaju O, Foulkes MJ, et al. Phenotyping pipeline reveals major seedling root growth QTL in hexaploid wheat. J Exp Bot. 2015;66(8):2283-92.

19. Maccaferri M, El-Feki W, Nazemi G, Salvi S, Canè MA, Colalongo MC, et al. Prioritizing quantitative trait loci for root system architecture in tetraploid wheat. J Exp Bot. 2016:67(4):1161-78.

20. Andrew R, Solanki S. Comparative root morphology for inbred lines of corn as related to performance. Agron J. 1966;58:415-8.

21. Naz AA, Arifuzzaman M, Muzammil S, Pillen K, Léon J. Wild barley introgression lines revealed novel QTL alleles for root and related shoot traits in the cultivated barley (Hordeum vulgare L.). BMC Genet. 2014;15:107.

22. Singh V, van Oosterom E, Jordan DR, Messina CD, Cooper M, Hammer GL. Morphological and architectural development of root systems in sorghum and maize. Plant Soil. 2010;333:287

23. Zhu J, Kaeppler SM, Lynch JP. Mapping of QTL for lateral root branching and length in maize (Zea mays L.) under differential phosphorus supply. Theor Appl Genet. 2005:111:688-95.

24. Laperche A, Devienne-Barret F, Maury O, Le Gouis J, Ney B. A simplified conceptual model of carbon/nitrogen functioning for QTL analysis of winter wheat adaptation to nitrogen deficiency. Theor Appl Genet. 2006;113:1131-46.

25. Li H, Vaillancourt R, Mendham N, Zhou M. Comparative mapping of quantitative trait loci associated with waterlogging tolerance in barley (Hordeum vulgare L.). BMC Genomics. 2008:9:401.

26. Liu X, Li R, Chang X, Jing R. Mapping QTL for seedling root traits in a doubled haploid wheat population under different water regimes. Euphytica. 2013;189:51-66.

27. Heeraman DA, Hopmans JW, Clausnitzer V. Three dimensional imaging of plant roots in situ with X-ray computed tomography. Plant Soil. 1997;189: 167-79.

28. Tracy S, Roberts J, Black C, McNeill A, Davidson R, Mooney S. The X-factor: visualizing undisturbed root architecture in soils using $X$-ray computed tomography. J Exp Bot. 2010:61:311-3.

29. Mooney SJ, Pridmore TP, Helliwell J, Bennett MJ. Developing X-ray computed tomography to non-invasively image 3-D root systems architecture in soil. Plant Soil. 2012;352:1-22

30. Daly K, Cooper L, Koebernick N, Evaristo J, Keyes S, van Veelen A, Roose T. Water dynamics in the rhizosphere. Rhizosphere. 2017;4:139-51.

31. Walter A, Schurr U. Dynamics of leaf and root growth: endogenous control versus environmental impact. Ann Bot. 2005;95:891-900.

32. Hoffmann A, Maurer A, Pillen K. Detection of nitrogen deficiency QTL in juvenile wild barley introgression lines growing in a hydroponic system. BMC Genet. 2012;13:88.

33. Arifuzzaman M, Sayed MA, Muzammil S, Pillen K, Schumann $H$, Naz AA, Léon J. Detection and validation of novel QTL for shoot and root traits in barley (Hordeum vulgare L.). Mol Breed. 2014;34(3):1373-87.

34. Kumar B, Abdel-Ghani AH, Pace J, Reyes-Matamoros J, Hochholdinger F Lübberstedt T. Association analysis of single nucleotide polymorphisms in candidate genes with root traits in maize (Zea mays L.) seedlings. Plant Sci. 2014;224:9-19

35. Tuberosa R, Salvi S, Sanguineti MC, Maccaferri M, Giuliani S, Landi P. Searching for quantitative trait loci controlling root traits in maize: a critical appraisal. Plant Soil. 2003;255(1):35-54.

36. Baum M, Grando S, Backes G, Jahoor A, Sabbagh A, Ceccarelli S. QTL for agronomic traits in the Mediterranean environment identified in recombinant inbred lines of the cross "Arta" $\times \mathrm{H}$. spontaneum 41-1. Theor Appl Genet. 2003;107:1215-25 
37. Ivandic V, Thomas WTB, Nevo E, Zhang Z, Forster BP. Associations of simple sequence repeats with quantitative trait variation including biotic and abiotic stress tolerance in Hordeum spontaneum. Plant Breed. 2003;122: $300-4$.

38. Teulat B, Zoumarou-Wallis N, Rotter B, Ben Salem M, Bahri H, This D. QTL for relative water content in field-grown barley and their stability across Mediterranean environments. Theor Appl Genet. 2003;108(1):181-8.

39. Xue D, Zhou M, Zhang X, Chen S, Wei K, Zeng F, et al. Identification of QTL for yield and yield components of barley under different growth conditions. J Zhejiang Univ Sci B. 2010;11(3):169-76.

40. Woll K, Borsuk LA, Stransky H, Nettleton D, Schnable PS, Hochholdinger F. Isolation, characterization, and pericycle-specific transcriptome analyses of the novel maize lateral and seminal root initiation mutant rum1. Plant Physiol. 2005;139:1255-67.

41. Champoux MC, Wang G, Sarkarung S, Mackill DJ, O'Toole JC, Huang N, McCouch SR. Locating genes associated with root morphology and drought avoidance in rice via linkage to molecular markers. Theor Appl Genet. 1995;90:969-81.

42. Hetz W, Hochholdinger F, Schwall M, Feix G. Isolation and characterization of rtcs, a maize mutant deficient in the formation of nodal roots. Plant $\mathrm{J}$. 1996;10:845-57.

43. Wang M, Jiang N, Jia T, Leach L, Cockram J, Waugh R, et al. Genome-wide association mapping of agronomic and morphologic traits in highly structured populations of barley cultivars. Theor Appl Genet. 2012;124(2): 233-46.

44. Neumann K, Kobiljski B, Denčić S, Varshney RK, Börner A. Genome-wide association mapping: a case study in bread wheat (Triticum aestivum L.). Mol Breed. 2011;27(1):37-58.

45. Stich B, Melchinger A. An introduction to association mapping in plants. CAB Rev. 2010:5:1-9.

46. Pasam RK, R. Sharma R, Malosetti M, van Eeuwijk FA, Haseneyer G, Kilian B, Graner A. Genome-wide association studies for agronomical traits in a world wide spring barley collection. BMC Plant Biol 2012;12:16.

47. Courtois B, Ahmadi N, Khowaja F, Price AH, Rami JF, Frouin J, Hamelin C, Ruiz M. Rice root genetic architecture: meta-analysis from a drought QTL database. Rice. 2009;2:115-28.

48. Ahmad Naz A, Ehl A, Pillen K, Léon J. Validation for root-related quantitative trait locus effects of wild origin in the cultivated background of barley (Hordeum vulgare L.). Plant Breed. 2012;131(3):392-8.

49. Zaare $\mathbf{M}$, Jafary $\mathrm{H}$. Quantitative trait loci diversity for salt tolerance at the early growth stage of barley. Crop Breed J. 2013;3:69-77.

50. George TS, Brown LK, Ramsay L, White PJ, Newton AC, Bengough AG, Russell J, Thomas WTB. Understanding the genetic control and physiological traits associated with rhizosheath production by barley (Hordeum vulgare). New Phytol. 2014;203:195-205.

51. Reinert S, Kortz A, Léon J, Naz AA. Genome-wide association mapping in the global diversity set reveals new QTL controlling root system and related shoot variation in barley. Front Plant Sci. 2016;19, 7

52. Sharma S, Xu S, Ehdaie B, Hoops A, Close TJ, Lukaszewski AJ, Waines JG Dissection of QTL effects for root traits using a chromosome arm-specific mapping population in bread wheat. Theor Appl Genet. 2011;122:759-69.

53. Canè MA, Maccaferri M, Nazemi G, Salvi S, Francia R, Colalongo C, Tuberosa R. Association mapping for root architectural traits in durum wheat seedlings as related to agronomic performance. Mol Breed. 2014;34(4):1629-45.

54. Hamada A, Nitta M, Nasuda S, Kato K, Fujita M, Matsunaka, et al. Novel OTLs for growth angle of seminal roots in wheat (Triticum aestivum L.). Plant Soil 2012;354:395-405.

55. Cai H, Chen F, Mi G, Zhang F, Maurer HP, Liu W, et al. Mapping QTLs for root system architecture of maize (Zea mays $L$.) in the field at different developmental stages. Theor Appl Genet. 2012;125:1313-24.

56. Burton AL, Johnson JM, Foerster JM, Hirsch CN, Buell CR, Kaeppler SM, Brown KM, Lynch JP. QTL mapping and phenotypic variation for root architectural traits in maize (Zea mays L.). Theor Appl Genet. 2014;127:2293-311.

57. Hund A, Reimer R, Messmer R. A consensus map of QTLs controlling the root length of maize. Plant Soil. 2011;344:143-58.

58. Shelden MC, Roessner U, Sharp RE, Tester M, Bacic A. Genetic variation in the root growth response of barley genotypes to salinity stress. Funct Plant Biol. 2013;40(5):516-30.

59. Long NV, Dolstra O, Malosetti M, Kilian B, Graner A, Visser RG, van der Linden CG. Association mapping of salt tolerance in barley (Hordeum vulgare L.). Theor Appl Genet. 2013;126:2335-51.
60. Li SB, Xie ZZ, Hu CG, Zhang JT. A review of auxin response factors (ARFs) in plants. Front Plant Sci. 2016;7:47.

61. B. Orosa-Puente B, Leftley N, von Wagenheim D, Banda J, Srivastava AK, Hill $\mathrm{K}$, et al. Root branching toward water involves posttranslational modification of transcription factor ARF7. Science. 2018;362(6421):14071410.

62. Tombuloglu H. Genome-wide analysis of the auxin response factors (ARF) gene family in barley (Hordeum vulgare L.). J Plant Biochem Biotechnol. 2018; doi.org/10.1007/s13562-018-0458-6.

63. Uga Y, Sugimoto K, Ogawa S, Rane J, Ishitani M, Hara N, et al. Control of root system architecture by DEEPER ROOTING 1 increases rice yield under drought conditions. Nat Genet. 2013;45(9):1097-102.

64. Kwasniewski M, Szarejko I. Molecular cloning and characterization of betaexpansin gene related to root hair formation in barley. Plant Physiol. 2006; 141:1149-58.

65. Kaur R, Sing K, Sing J. A root-specific wall-associated kinase gene, HVWAK1, regulates root growth and is highly divergent in barley and other cereals. J Funct Integr Genomics. 13(2):167-77.

66. Wojciechowski T, Gooding MJ, Ramsay L, Gregory PJ. The effects of dwarfing genes on seedling root growth of wheat. J Exp Bot. 2009;60(9): 2565-73.

67. Chloupek O, Forster BP, Thomas WTB. The effect of semi-dwarf genes on root system size in field-grown barley. Theor Appl Genet. 2006;122(5):77986.

68. Voss-Fels KP, Robinson H, Mudge SR, Richard C, Newman S, Wittkop B, et al. VERNALIZATION1 modulates root system architecture in wheat and barley. Mol Plant. 2018;11:226-9.

69. Abdel-Ghani AH, Neumann K, Wabila C, Sharma R, Dhanagond S, Owais SJ, Börner A, Graner A, Kilian B. Diversity of germination and seedling traits in a spring barley (Hordeum vulgare L.) collection under drought simulated conditions. Genet Resour Crop Evol. 2015;62(2):275-92.

70. Mascher M, Gundlach H, Himmelbach A, Beier S, Twardziok SO, Wicker T, et al. A chromosome conformation capture ordered sequence of the barley genome. Nature. 2017;544(7651):427-33.

71. Stracke S, Haseneyer G, Veyrieras J-B, Geiger HH, Sauer S, Graner A, Piepho $H-P$. Association mapping reveals gene action and interactions in the determination of flowering time in barley. Theor Appl Genet. 2009;118(2): 259-73.

72. Alqudah AM, Sharma R, Pasam RK, Graner A, Kilian B, Schnurbusch T. Genetic dissection of photoperiod response based on gwas of pre-anthesis phase duration in spring barley. PLoS One. 2014;9(11):1-27.

73. Yousseff HM, Eggert K, Koppolu R, Alqudah AM, Poursarebani N, Fazeli A, Sakuma S, Tagiri A, Rutten T, Govind G. VRS2 regulates hormone-mediated inflorescence patterning in barley. Nat Genet. 2017;49:157-61.

74. Klukas C, Chen D, Pape J-M. Integrated analysis platform: an open-source information system for high-throughput plant phenotyping. Plant Physiol. 2014:165(2):506-18.

75. Hallauer AM, Miranda JB. Quantitative genetics in maize breeding. 2nd ed. lowa State University Press, Ames, lowa, United States of America. 1981;1-468.

76. R Foundation for statistical computing. R: a language and environment for statistical computing. R Foundation for statistical computing. Vienna, Austria; 2016. URL http://www.R-project.org/

77. Comadran J, Kilian B, Russell J, Ramsay L, Stein N, Ganal M, et al. Natural variation in a homolog of Antirrhinum CENTRORADIALIS contributed to spring growth habit and environmental adaptation in cultivated barley. Nat Genet. 2012;44(12):1388-92.

78. Mascher M, Muehlbauer GJ, Rokhsar DS, Chapman J, Schmutz J, Barry K, et al. Anchoring and ordering NGS contig assemblies by population sequencing (POPSEQ). Plant J. 2013;76:718-27.

79. Tang Y, Liu X, Wang J, Li M, Wang Q, Tian F, et al. GAPIT version 2: an enhanced integrated tool for genomic association and prediction. Plant Genome. 2016;9(2).

80. Wang Q, Tian F, Pan Y, Buckler ES, Zhang Z. A super powerful method for genome wide association study. PLoS One. 2014;9(9):e107684.

81. Benjamini Y, Hochberg Y. Controlling the false discovery rate: a practical and powerful approach to multiple testing. J R Stat Soc B. 1995;57(57):289-300.

82. Voorrips RE. MapChart: software for the graphical presentation of linkage maps and QTLs. J Hered. 2002;93(1):77-8.

83. Colmsee C, Beier S, Himmelbach A, Schmutzer T, Scholz U, Mascher M. BARLEX - the barley draft genome explorer. Mol Plant. 2015;8:964-6. 
84. Milner SG, Jost M, Taketa S, Mazón ER, Himmelbach A, Oppermann M, et al. Genebank genomics highlights the diversity of a global barley collection. Nat Genet. 2019;51:319-26.

85. Untergasser A, Cutcutache I, Koressaar T, Ye J, Faircloth BC, Remm M, Rozen SG. Primer3 - new capabilities and interfaces. Nucleic Acids Res. 2012;40(15):e115.

86. Hall TA. BioEdit: a user-friendly biological sequence alignment editor and analysis program for windows 95/98/NT. Nucleic Acids Symp Ser. 1999;41: 95-8.

87. Rozas J, Ferrer-Mata A, Sánchez-DelBarrio JC, Guirao-Rico S, Librado P, Ramos-Onsins SE, Sánchez-Gracia A. DnaSP 6: DNA sequence polymorphism analysis of large data sets. Mol Biol Evol. 2017;34(12):3299-302.

88. Neumann K, Zhao Y, Chu J, Keilwagen J, Reif JC, Kilian B, Graner A. Genetic architecture and temporal patterns of biomass accumulation in spring barley revealed by image analysis. BMC Plant Biol. 2017;17(1).

89. Wehner G, Balko C, Enders M, Humbeck K, Ordon F. Identification of genomic regions involved in tolerance to drought stress and drought stress induced leaf senescence in juvenile barley. BMC Plant Biol. 2015;15:125.

90. Mora F, Quitral YA, Matus I, Russell J, Waugh R, del Pozo A. SNP-based QTL mapping of 15 complex traits in barley under rain-fed and well-watered conditions by a mixed modeling approach. Front Plant Sci. 2016;7:909.

91. Fletcher RS, Mullen JL, Heiliger A, McKay JK. QTL analysis of root morphology, flowering time, and yield reveals trade-offs in response to drought in Brassica napus. J Exp Bot. 2014;66(1):245-56.

92. Deveaux Y, Toffano-Nioche C, Claisse G, Thareau V, Morin H, Laufs P, et al. Genes of the most conserved WOX clade in plants affect root and flower development in Arabidopsis. BMC Evolutionary Biol. 2008;8:291.

93. Digel B, Tavakol E, Verderio G, Tondelli A, Xu X, Cattivelli L, Rossini L, von Korff M. Photoperiod1 (Ppd-H1) controls leaf size. Plant Physiol. 2016;172(1) 405-15.

94. Habte E, Muller LM, Shtaya M, Davis SJ, Von Korff M. Osmotic stress at the barley root affects expression of circadian clock genes in the shoot. Plant Cell Environ. 2014;37:1321-7.

95. Mizuno T, Yamashino T. Comparative transcriptome of diurnally oscillating genes and hormone-responsive genes in Arabidopsis thaliana: insight into circadian clock-controlled daily responses to common ambient stresses in plants. Plant Cell Physiol. 2008;49:481-7.

96. Müller A, Guan C, Gälweiler L, Tänzler P, Huijser P, Marchant A, Parry G, Bennett M, Wisman E, Palme K. AtPIN2 defines a locus of Arabidopsis for root gravitropism control. EMBO J. 1998;17:6903-11.

97. Utsuno K, Shikanai T, Yamada Y, Hashimoto T. AGR, an agravitropic locus of Arabidopsis thaliana, encodes a novel membrane-protein family member. Plant Cell Physiol. 1998;39:1111-8.

98. Mravec J, Skůpa P, Bailly A, Hoyerová K, Bielach A, Petrášek J, et al. Subcellular homeostasis of phytohormone auxin is mediated by the ERlocalized PIN5 transporter. Nature. 2009;459:1136-40.

99. Friml J. Auxin transport-shaping the plant. Curr Opin Plant Biol. 2003;6:7-12.

100. Ding ZJ, Wang BJ, Moreno I, Dupláková N, Sibu S, Carraro N, et al. ERlocalized auxin transporter PIN8 regulates auxin homeostasis and male gametophyte development in Arabidopsis. Nat Commun. 2012;3:941.

101. Rosquete MR, Waidmann S, Kleine-Vehn J. PIN7 auxin carrier has a preferential role in terminating radial root expansion in Arabidopsis thaliana. Int J Mol Sci. 2018;19(4):1238.

102. Křeček P, Skůpa P, Libus J, Naramoto S, Tejos R, Friml J, Zažímalová E. The pinformed (pin) protein family of auxin transporters. Genome Biol. 2009;10:249.

103. Richter S, Anders N, Wolters H, Beckmann H, Thomann A, Heinrich R, et al. Role of the GNOM gene in Arabidopsis apical-basal patterning - from mutant phenotype to cellular mechanism of protein action. Eur J Cell Biol. 2010;89:138-44.

104. Kohli P, Kalia M, Gupta R. Pectin Methylesterases: a review. J Bioprocess Biotech. 2015;5:5.

105. Yang XY, Zeng ZH, Yan JY, Fan W, Bian HW, Zhu MJ, et al. Association of specific pectin methylesterases with Al-induced root elongation inhibition in rice. Physiol Plant. 2013;148:502-11.

106. Daher BF, Chen Y, Bozorg B, Clough J, Jonsson H, Braybrook SA. Anisotropic growth is achieved through the additive mechanical effect of material anisotropy and elastic asymmetry. Elife. 2018;7:e38161.

107. Marchant A, Bhalerao R, Casimiro I, Eklöf J, Casero PJ, Bennett M, Sandberg G. AUX1 promotes lateral root formation by facilitating indole-3-acetic acid distribution between sink and source tissues in the Arabidopsis seedling. Plant Cell. 2002;14(3):589-97.
108. Chmielewska B, Janiak A, Karcz J, Guzy-Wrobelska J, Forster BP, Nawrot M, et al. Morphological, genetic and molecular characteristics of barley root hair mutants. J Appl Genet. 2014;55(4):433-47.

109. Inukai Y, Sakamoto T, Ueguchi-Tanaka M, Shibata Y, Gomi K, Umemura I, et al. Crown rootless 1, which is essential for crown root formation in rice, is a target of an AUXIN RESPONSE FACTOR in auxin signaling. Plant Cell. 2005. 17:1387-96.

110. Liu H, Wang S, Yu X, Yu J, He X, Zhang S, Shou H, Wu P. ARL1, a LOBdomain protein required for adventitious root formation in rice. Plant $J$. 2005;43(1):47-56.

111. Taramino G, Sauer M, Stauffer UL, Multani D, Niu X, Sakai H, Hochholdinger F. The maize (Zea mays L.) RTCS gene encodes a LOB domain protein that is a key regulator of embryonic seminal and post-embryonic shoot-borne root initiation. Plant J. 2007:50:649-59.

112. Rohde W, Becker D, Salamini F. Structural analysis of the waxy locus from Hordeum vulgare. Nucleic acids res. 1988;16:7185-718662. Turner a, Beales J, Faure S, Dunford RP, D.a. Laurie DA. The Pseudo-Response Regulator Ppd-H1 provides adaptation to photoperiod in barley. Science. 2005:310(5750):1031-4.

113. Douchkov D, Lück S, Johrde A, Nowara D, Himmelbach A, Rajaraman J, Stein N, Sharma R, Kilian B, Schweizer P. Discovery of genes affecting resistance of barley to adapted and non-adapted powdery mildew fungi. Genome Biol. 2014;15(12):518.

114. Mikołajczak K, Ogrodowicz P, Gudyś K, Krystkowiak K, Sawikowska A, Frohmberg W, et al. Quantitative trait loci for yield and yield-related traits in spring barley populations derived from crosses between European and Syrian cultivars. PLoS One. 2016;11(5):e0155938.

115. Sharma R, Draicchio F, Bull H, Herzig P, Maurer A, Pillen K, Thomas W, Flavell AJ. Genome-wide association of yield traits in a nested association mapping population of barley reveals new gene diversity for future breeding. Jounal Exp Bot. 2018;69(16):3811-22.

116. Xu X, Sharma R, Tondelli A, Russell J, Comadran J, Schnaithmann F, et al. Genome-wide association analysis of grain yield-associated traits in a PanEuropean barley cultivar collection. Plant Genome. 2018;11(1). https://doi. org/10.3835/plantgenome2017.08.0073.

117. Varshney RK, Gaur PM, ChamaRth SK, Krishnamurthy L, Tripathi S, Kashiwagi J, et al. Fast-track introgression of "QTL-hotspot" for root traits and other drought tolerance traits in JG 11, an elite and leading variety of chickpea. Plant Genome. 2013;6(3):1-9.

118. Bull H, Casao MC, Zwirek M, Flavell AJ, Thomas WTB, Guo W, et al. Barley SIX-ROWED SPIKE3 encodes a putative Jumonji C-type H3K9me2/me3 demethylase that represses lateral spikelet fertility. Nat Commun. 2017;8(1): $1-9$.

119. van Esse GW, Walla A, Finke A, Koornneef M, Pecinka A, von Korff M. Sixrowed spike 3 (VRS3) is a histone demethylase that controls lateral spikelet development in barley. Plant Physiol. 2017;174:2397-408.

120. Liller CB, Neuhaus R, Von Korff M, Koornneef M, Van Esse W. Mutations in barley row type genes have pleiotropic effects on shoot branching. PLoS One. 2015;10(10):1-20.

121. Werner T, Motyka V, Laucou V, Smets R, Van Onckelen $H$, Schmülling T. Cytokinin-deficient transgenic Arabidopsis plants show multiple developmental alterations indicating opposite functions of Cytokinins in the regulation of shoot and root meristem activity. Plant Cell. 2003; 15(11):2532-50

122. Osugi A, Sakakibara HQ. A: how do plants respond to cytokinins and what is their importance? BMC Biol. 2015;13:102.

123. Alqudah AM, Koppolu R, Wolde GM, Graner A, Schnurbusch T. The genetic architecture of barley plant stature. Front Genet. 2016;7:117.

124. Maurer A, Draba V, Jiang Y, Schnaithmann F, Sharma R, Schumann E, et al. Modelling the genetic architecture of flowering time control in barley through nested association mapping. BMC Genomics. 2015;16:290.

125. Maurer A, Draba V, Pillen K. Genomic dissection of plant development and its impact on thousand grain weight in barley through nested association mapping. J Exp Bot. 2016;67(8):2507-18.

126. Ingvordsen $\mathrm{CH}$, Backes $\mathrm{G}$, Lyngkjær MF, Peltonen-Sainio $\mathrm{P}$, Jahoor A, Mikkelsen TN, Jørgensen RB. Genome-wide association study of production and stability traits in barley cultivated under future climate scenarios. Mol Breed. 2015:35:84

127. Sannemann W, Huang BE, Mathew B, Leon J. Multi-parent advanced generation inter-cross in barley: high-resolution quantitative trait locus mapping for flowering time as a proof of concept. Mol Breed. 2015;35:86. 
128. Alqudah AM, Youssef HM, Graner A, Schnurbusch T. Natural variation and genetic make-up of leaf blade area in spring barley. Theor Appl Genet. 2018;131:873-86.

129. Turner A, Beales J, Faure S, Dunford RP, Laurie DA. DA. The pseudoresponse regulator $\mathrm{Ppd}-\mathrm{H} 1$ provides adaptation to photoperiod in barley. Science. 2005:310(5750):1031-4.

130. Baker K, Bayer M, Cook N, Dressig S, Dhillon T, Russell J, et al. The lowrecombining pericentromeric region of barley restricts gene diversity and evolution but not gene expression. Plant J. 2014;79:981-92.

131. Helariutta Y, Fukaki H, Wysocka-Diller J, Nakajima K, Jung J, Sena G, Hauser MT, Benfey PN. The SHORT-ROOT gene controls radial patterning of the Arabidopsis root through radial signaling. Cell. 2000;101(5):555-67.

132. Benitez-Alfonso Y, Jackson D. Redox homeostasis regulates plasmodesmal communication in Arabidopsis meristems. Plant Signal Behav. 2009;4(7):655-9.

133. Velasquez SM, Ricardi MM, Poulsen CP, Oikawa A, Dilokpimol A, Halim A, et al. Complex regulation of prolyl-4-hydroxylases impacts root hair expansion. Mol Plant. 2015:8(5):734-46.

134. Sakuma S, Pourkheirandish M, Hensel G, Kumlehn J, Stein N, Tagiri A, et al. Divergence of expression pattern contributed to neofunctionalization of duplicated HD-zip I transcription factor in barley. New Phytol. 2013;197(3): 939-48.

135. de la Rosa Santamaria R, Shao MR, Wang G, Nino-Liu DO, Kundariya H, et al. MSH1-induced non-genetic variation provides a source of phenotypic diversity in Sorghum bicolor. PLoS One. 2014;9(10):e108407.

136. Virdi KS, Laurie JD, Xu Y-Z, Yu J, Shao M-R, Sanchez R, et al. Arabidopsis $\mathrm{MSH} 1$ mutation alters the epigenome to produce heritable changes in plant growth. Nat Commun. 2015;6:6386.

137. Virdi KS, Wamboldt Y, Kundariya H, Laurie JD, Keren I, Kumar KS, Block A, et al. MSH1 is a plant organellar DNA binding and thylakoid protein under precise spatial regulation to alter development. Mol Plant. 2016;9:245-60.

138. Nair SK, Wang N, Turuspekov Y, Pourkheirandish M, Sinsuwongwat S, Chen $\mathrm{G}$, et al. Cleistogamous flowering in barley arises from the suppression of microRNA-guided HvAP2 mRNA cleavage. Proc Natl Acad Sci. 2010;107(1): 490-5.

139. Houston K, McKim SM, Comadran J, Bonar N, Druka I, Uzrek N, et al. Variation in the interaction between alleles of HVAPETALA2 and microRNA172 determines the density of grains on the barley inflorescence. Proc Natl Acad Sci. 2013;110(41):16675-80.

140. Licausi F, Ohme-Takagi M, Perata P. APETALA2/ethylene responsive factor (AP2/ERF) transcription factors: mediators of stress responses and developmental programs. New Phytol. 2013;199(3):639-49.

141. Richter J, Ploderer M, Mongelard G, Gutierrez L, Hauser M-T. Role of CrRLK1L Cell Wall sensors HERCULES1 and 2, THESEUS1, and FERONIA in growth adaptation triggered by heavy metals and trace elements. Front Plant Sci. 2017:8:1554

142. Schwartz SH, Qin X, Zeevaart JAD. Elucidation of the indirect pathway of abscisic acid biosynthesis by mutants. Genes, and Enzymes Plant Physiol. 2003;131(4):1591-601.

143. Harris JM. Abscisic acid: hidden architect of root system structure. Plants (Basel). 2015;4(3):548-72.

144. Sharp RE, LeNoble ME. ABA, ethylene and the control of shoot and root growth under water stress. J Exp Bot. 2002;53(366):33-7.

145. Rollins JA, Drosse B, Mulki MA, Grando S, Baum M, Singh M, S. Ceccarelli A, von Korff M. Variation at the vernalisation genes $\mathrm{Vrn}-\mathrm{H} 1$ and $\mathrm{V} r n-\mathrm{H} 2$ determines growth and yield stability in barley (Hordeum vulgare) grown under dryland conditions in Syria. Theor Appl Genet 2013;126(11):2803-2824.

146. Griffiths S, Dunford RP, Coupland G, Laurie DA. The evolution of CONSTANSlike gene families in barley, rice, and Arabidopsis. Plant Physiol. 2003;131(4): 1855-67.

147. Cockram J, Thiel T, Steuernagel B, Stein N, Taudien S, Bailey PC, O'Sullivan DM. Genome dynamics explain the evolution of flowering time CCT domain gene families in the Poaceae. PLoS One. 2012;7(9):e45307.

148. Campoli C, Drosse B, Searle I, Coupland G, Von Korff M. Functional characterisation of HvCO1, the barley (Hordeum vulgare) flowering time ortholog of CONSTANS. Plant J. 2012;69(5):868-80.

149. Calixto CPG, Simpson CG, Waugh R, Brown JWS. Alternative splicing of barley clock genes in response to low temperature. PLoS One. 2016;11(12): e0168028.

150. Li XY, Qian Q, Fu ZM, Wang YH, Xiong GS, et al. Control of tillering in rice. Nature. 2003;422:618-21.
151. Zhang XH, Rao XL, Shi HT, Li RJ, Lu YT. Overexpression of a cytosolic glyceraldehyde-3-phosphate dehydrogenase gene OsGAPC3 confers salt tolerance in rice. Plant Cell Tissue Organ Cult. 2011;107:1-11.

152. Knoch E, Dilokpimol A, Tryfona T, Poulsen CP, Xiong G, Harholt J, et al. A beta-glucuronosyltransferase from Arabidopsis thaliana involved in biosynthesis of type II arabinogalactan has a role in cell elongation during seedling growth. Plant J. 2013;76:1016-29.

153. Guo M, Liu J-H, Ma X, Luo D-X, Gong Z-H, Lu M-H. The plant heat stress transcription factors (HSFs): structure, regulation, and function in response to abiotic stresses. Front Plant Sci. 2016;7:114.

154. Osakabe Y, Arinaga N, Umezawa T, Katsura S, Nagamachi K, Tanaka H, Ohiraki H, Yamada K, Seo S-U, Abo M, et al. Osmotic stress responses and plant growth controlled by potassium transporters in Arabidopsis. Plant Cell. 2013;25:609-24

155. Graether SP, Boddington KF. Disorder and function: a review of the dehydrin protein family. Front Plant Sci. 2014:5:576.

156. Trevaskis B, Tadege M, Hemming MN, Peacock WJ, Dennis ES, Sheldon C. Short vegetative phase-like MADS-box genes inhibit floral meristem identity in barley. Plant Physiol. 2007;143:225-35.

157. Kim SY. The role of ABF family bZIP class transcription factors in stress response. Physiol Plant. 2006;126:519-27.

158. Uno Y, Furihata $T$, Abe $H$, Yoshida R, Shinozaki K, Yamaguchi-Shinozaki K Arabidopsis basic leucine zipper transcription factors involved in an abscisic acid-dependent signal transduction pathway under drought and highsalinity conditions. Proc Natl Acad Sci U S A. 2000;97:11632-7.

159. Kim S, Kang JY, Cho DI, Park JH, Kim SY. ABF2, an ABRE-binding bZIP factor, is an essential component of glucose signaling and its overexpression affects multiple stress tolerance. Plant J. 2004;40(1):75-87.
Ready to submit your research? Choose BMC and benefit from:

- fast, convenient online submission

- thorough peer review by experienced researchers in your field

- rapid publication on acceptance

- support for research data, including large and complex data types

- gold Open Access which fosters wider collaboration and increased citations

- maximum visibility for your research: over $100 \mathrm{M}$ website views per year

At $\mathrm{BMC}$, research is always in progress.

Learn more biomedcentral.com/submissions 